\title{
INFLUENCE OF PH ON THE LOCALIZED CORROSION OF IRON
}

\author{
MIT/BNL-86-6 \\ R. Webley and R. Henry \\ Consultants: \\ H. Isaacs and G. Cragnolino
}

BNL- -39687

DE87 010452

June 1986

BROOKHAVEN STATION

SCHOOL OF CHEMICAL ENGINEERING PRACTICE

MASSACHUSETTS IMSTITUTE OF TECHNOLOGY

R.D. SPROULL, DIRECTOR

F.J. HRACH, ASSISTANT DIRECTOR

\author{
DEPARTMENT OF APPLIED SCIENCE \\ BROOKHAVEN MATIOMAL LABORATORY \\ ASSOCIATED UMIVERSITIES, INC. \\ UPTON, LONG ISLAND, NEW YDRK 11973
}

UNDER CONTRACT NO. DE-ACO2-76CHO0016 WITH THE UNITED STATES DEPARTMENT OF ENERGY 


\section{DISCLAIMER}

This report was prepared as an account of work sponsored by an agency of the United States Government. Neither the United States Government nor any agency thereof, nor any of their employees, nor any of their contractors, subcontractors, or their employees, makes any warranty, express or implied, or assumes any legal liability or responsibility for the accuracy, completeness, or usefulness of any information, apparatus. product, or process disclosed, or represents that its use would not infinge privately owned rights. Reference herein to any specific commercial product, process, or service by trade name, trademark, manufacturer, or otherwise, does not necessarily constitute or imply its endorsement, recommendation, or favoring by the United Staces Government or any agency, contractor or subcontractor thereof. The views and opinions of authors expressed herein do not necessarily state or reflect those of the United States Government or any agency, contractor or subcontractor thereof. 


\section{ABSTRACT}

The influence of $\mathrm{pH}$ on the pitting corrosion of iron in chloride and sulfate solutions was determined using two artificial pit apparatuses to obtain the $\mathrm{pH}$ near the surface of the pit bottom. A glass membrane electrode and an antimony electrode were used to measure $\mathrm{pH}$ in the two apparatuses. Using solutions of $\mathrm{NaCl}$ and $\mathrm{Na}_{2} \mathrm{SO}_{4}$ at current densities of $0.5,5.0$, and $10 \mathrm{~mA} / \mathrm{cm}^{2}$ $\mathrm{pH}$ 's in the range 5 to 6 were obtained with the first apparatus. The antimony probe did not measure $\mathrm{pH}$ accurately in solutions of $1 \mathrm{~N} \mathrm{NaCl}$ and $1 \mathrm{~N} \mathrm{Na}_{2} \mathrm{SO}_{4}$ and had an error of approximately $2 \mathrm{pH}$ units. A one-dimensional transport model was developed to predict $\mathrm{pH}$ variations around the pit mouth and inside the pit. The validity of this model was not verified due to the relative lack of precision with $\mathrm{pH}$ measurement techniques.

Funding support for this project has also been provided by the Nuclear Regulatory Commission, office of Nuclear Regulatory Research, Contract No. $\mathrm{DE}-\mathrm{ACO2}-76 \mathrm{CHO0016}$, FIN 3269. Funding for the overall program is provided on a continuing basis from the Department of Energy. 
1. SUMMARY........................................ 1

2. INTRODUCTION..................................... 3

2.1 Background and Motivation........................ 3

2.2 Objectives and Method of Approach.................. 5

3. THEORY OF PITTING CORROSION ......................... 7

3.1 Passlvity of Metals............................. 7

3.2 Initiation of Pitting and Pit Growth................ 7

3.3 Factors Affecting Pitting........................ 10

3.3.1 Anion Concentration......................... 10

3.3 .2 Current Denstty.......................... 10

3.3.3 BuIk pH of Electrolyte.................... 10

3.4 Measurement of $\mathrm{pH} . \ldots \ldots \ldots \ldots \ldots \ldots \ldots \ldots \ldots \ldots \ldots \ldots \ldots \ldots \ldots \ldots . \ldots \ldots$

4. MOdELING pH VARIATIONS IN AND AROUND PIT.................. 13

4.1 Modeling Ion Transport in Corroding Pits............. 13

4.2 One-Dimensional Transport Outside a Corroding P1t....... 14

4.2.1 Model Derivation with no Cathodic Reaction........ 14

4.2.2 Model Derivation with a Cathodic Reaction......... 18

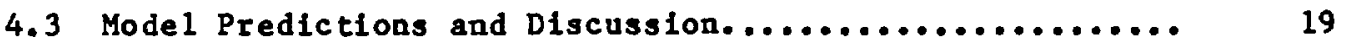

4.3 .1 pH Profiles................................ 19

4.3.2 Conditions at the Pit Mouth................. 21

5. EXPERIMENTAL APPARATUS AND PROCEDURE..................... 27

5.1 Artificial Pit Apparatus......................... 27

5.2 Experimental Procedure.......................... 33

5.2.1 Measurement of $\mathrm{pH}$ and Potentlal with the

Flat-Bottoned $\mathrm{pH}$ Probes....................... 33

5.2.2 Attempt to measure $\mathrm{pH}$ Profile In an Artificial

Pit with Flat-Bottomed Probes.................. 34

5.2.3 Measurement of the pH Profile in an Artificial

Pit with Antimony $\mathrm{pH}$ Micro-Probes............. 34

6. EXPERIMENTAL RESULTS AND DISCUSSION..................... 35

6.1 Flat-Bottomed Probe Apparatus..................... 35

6.1 .1 Potential and $\mathrm{pH}$ Changes.................... 35

6.1 .2 pH Estimation............................ 38

6.1.3 At tempted Measurement of $\mathrm{pH}$ Profile in an

Artificial Pit........................... 45

6.2 Antimony Probe Apparatus....................... 45

6.2 .1 Behavfor of the Antimony pH Probe.............. 45

6.2.2 Measurement of $\mathrm{pH}$ Profiles and

Comparison with Predicted Profiles............. 48

6.3 Utility of Experimental Apparatuses................. 51

6.3.1 Flat-Bottomed Probe Apparatus................ 51

6.3 .2 Antimony Probe Apparatus.................... 51

6.3 .3 Comparison of Apparatuses................... 52

6.4 Results from other Apparatuses...................... 52 
TABLE OF CONTENTS (cont.)

Page

7. Concuusions............................... 53

7.1 Flat-Bottomed Probe Apparatus................. 53

7.2 Antimony Probe Apparatus................... 53

7.3 Modeling $\mathrm{pH}$ Variations...................... 53

8. RECOMMENDATIONS............................. 55

9. ACKNOWLEDGMENTS. ........................... 57

10. APPENDIX................................... 59

10.1 Nomenclature............................ 59

10.2 Numerical Calculations in Model Derivation......... 60

10.3 Calculation of the $\mathrm{pH}$ of a Ferrous Ion Solution.... 61

10.4 Location of Original Data.................... 62

11. REFERENCES ................................ 63 
$2-1$ Pit Initiation and Growth........................... 4

3-1 Pourbaix Diagram for Iron............................ 8

4-1 Transport Hodel Outside the Corroding Pit................. 16

4-2 pH Profiles Predicted by lodel I (no cathodic reaction)....... 22

4-3 pH Profiles Predicted by Model II (hydrogen reduction at cathode) ......................................... 24

5-1 Schematic One-Dimensiona 1 Artificial Pit Apparatus........... 28

5-2 Flat-Bottomed Probe Artificial Pit Apparatus................ 29

5-3 Antimony Probe Artificial Pit Apparatus.................. 30

$5-4$ Antimony $\mathrm{pH}$ Probe.................................. 32

6-1 Transient pH Behavior for 1 N NaCl....................... 36

6-2 Transient Potential Behavior for $1 \mathrm{~N}$ NaCl................. 37

6-3 Expected Ferrous Ion Concentration Profiles in the Artificial Pit Apparatus.............................. 39

6-4 Ferrous Ion Concentration Profile Using Simplification I................................... 40

6-5 Ferrous Ion Concentration Profiles Using Simplification II.................................. 41

6-6 Concentration of Ferrous Ions Using Simplifications I and II... 44

6-7 pH Profile in the Artificial Pit as Measured by the Flat-Bottomed Probe................................ 46

6-8 Antimony Probe Calibration............................ 47

6-9 Comparison of Experimental Data (Antimony Probe) with Model Predictions $\left(1=5 \mathrm{~mA} / \mathrm{cm}^{2}\right) \ldots \ldots \ldots \ldots \ldots \ldots \ldots \ldots \ldots \ldots \ldots \ldots \ldots \ldots \ldots \ldots \ldots \ldots \ldots$

6-10 Comparison of Experimental Data (Antimony Probe) with Model Predictions $\left(i=7 \mathrm{~mA} / \mathrm{cm}^{2}\right)$. 


\section{LIST OF TABLES}

Page

4-1 Physical Constants Used in the Mode1.....................

4-2 Predicted Concentrations of Iron Species at



4-3 Predicted Concentrations of Iron Specles at

Pit Mouth for Model II...............................

6-1 Reproducibility of the Flat-Bottomed Probe Apparatus

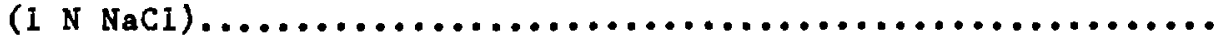

$6-2$ Antimony pH Probe Error........................... 


\section{SUMMARY}

In order to design long lasting radioactive waste containment vessels, the process of corrosion must be characterized so that the rate of corrosion can be predicted. In the absence of localized corrosion, the entire surface of a metal corrodes at a uniform rate. The rate of uniform corrosion is predictable, enabling designers to estimate the life of a containment vessel. If localized corrosion occurs, however, corrosion at one point on the metal surface is accelerated and the vessel may be perforated before its designed lifetime has expired.

Pitting, the most common form of localized corrosion, occurs via the formation of a galvanic cell at the iron surface exposed to an electrolytic solution. The iron surface is usually protected by a passive oxide film which prevents the corrosion process. However, cracks and imperfections in this film are potential sites for the initiation of pitting. Iron dissolution occurs at the bottom of the pit (anodic reaction) while a cathodic reaction, oxygen or hydrogen reduction, occurs at the surrounding metal surface. The iron ions in the pit solution hydrolyze to form hydrogen ions, lowering the phi locally. The decrease in $\mathrm{pH}$ inside the $\mathrm{pit}$ accelerates the growth of the pit by enhancing the dissolution of the metal. The cathodic reaction results in an increase in $\mathrm{pH}$ at the surface of the metal surrounding the pit due to the production of hydroxide ions or consumption of hydrogen ions. Therefore, the $\mathrm{pH}$ varies from the bottom of the pit to the surrounding metal surface.

Because dissolution of the oxide film is sensitive to the local pH of the solution, the $\mathrm{pH}$ profile characterizes the manner in which the pit grows. If the pit steadily deepens, the container will be breached prematurely; while a gradual spreading of pitting will lead to a uniform, predictable rate of corrosion. The objective of this project was to determine the influence of $\mathrm{pH}$ changes in unbuffered chloride and sulfat: solutions on the localized cor-. rosion of iron.

We used two experimental apparatuses to determine the magnitude of $\mathrm{pH}$ in the solution adjacent to the bottom surface of an artificial pit. The first apparatus simulated a pit $16 \mathrm{~mm}$ in diameter and $41 \mathrm{~mm}$ deep. A flat-bottomed glass nembrane $\mathrm{pH}$ probe of diameter $12 \mathrm{~mm}$ was inserted into pit to measure the pH approximately $1 \mathrm{~mm}$ from the iron surface. The solutions used in the apparatus were $1 \mathrm{~N}$ and $2 \mathrm{~N} \mathrm{NaCl}$ and $1 \mathrm{~N}$ and $2 \mathrm{~N} \mathrm{Na}_{2} \mathrm{SO}_{4} \cdot$ Current densities used were $0.5,5.0$, and $10 \mathrm{~mA} / \mathrm{cm}^{2}$. After applying current the $\mathrm{pH}$ and potential were recorded with time. The bulk pH of the electrolytic solution was in the range 6.5 to 7.5 , and the pH measured after 2 hours was in the range 5 to 6 . The runs were reproducible to approximately $0.5 \mathrm{pH}$ unit.

We felt that a diffusion model of the corrosion process would not be applicable to this apparatus because of the obtrusive nature of the probe. To account for the effect of the probe on the pH measured above the metal surface, two separate simplifications were made to calculate to Fet+ concentration profiles in the bottom of the pit. The first simplification was based on the assumption that the iron which had dissolved was uniformly contained in the rolume beneath the probe, while in the second simplification we made an estimate of the rate of diffusion out of the region near the probe. The first 
simplification resulted in calculated $\mathrm{Fe}^{++}$concentrations above that expected from the equilibrium at the measured pH. Because Fett diffuses past the $\mathrm{pH}$ probe to the bulk solution, we expected that the calculated Fe ${ }^{++}$ concentration would be higher than predicted from equilibrium considerations. The second simplification accounted for the removal of $\mathrm{Fe}^{++}$by diffusion and resulted in a good estimate of the Fett concentration at the measured ph.

In the second pit apparatus, we were able to measure the variation in $\mathrm{pH}$ as a function of height above the pit bottom. This second apparatus incorporated an antimony $\mathrm{pH}$ micro-probe (tip diameter $=0.4 \mathrm{~mm}$ ) so that the effect of the probe on the pH profile in the pit was effectively eliminated. The simulated pit had dimensions of $6 \mathrm{~mm}$ diameter and $18 \mathrm{~mm}$ deep. In this apparatus, the probe was moved vertically by increments of $0.6 \mathrm{~mm}$ and the pH measured at each point after the system had reached a "quasi-steady state". The "quasisteady state" was verified by recording identical profiles moving the probe both up and down at different times. The solutions studied were $1 \mathrm{~N} \mathrm{NaCl}$ and $1 \mathrm{~N} \mathrm{Na} \mathrm{SO}_{4}$ at current densities of 5 and $7 \mathrm{~mA} / \mathrm{cm}^{2}$. Although the antimony probe was carefully calibrated in a series of standard buffer solutions, its response in the solutions studied was incorrect, indicating a pH of 3 to 4 in a neutral solution. Although the results obtained with the probe are inaccurate, the small size of the probe allowed us to measure pH differences over distances less than $1 \mathrm{~mm}$.

We derived a one-dimensional transport model to predict $\mathrm{pH}$ variations around the mouth of a pit. From this model, we obtained the conditions at the mouth of the pit. Using these conditions and previously derived equations (Galvele, 1981) for one-dimensional transport inside the pit, we extended our model to perform calculations for the conditions at the metal surface at the bottom of the pit. Comparison of the predicted and experimental profiles indicated the poor accuracy of the antimony probes. We were therefore unable to verify the validity of the model.

The model outside the pit accounted for the presence of a cathode and predicted the $\mathrm{pH}$ variation with radial distance from the pit. For a bulk solution of $\mathrm{pH} 10$, there is a critical value of pit radius $\left(10^{-6} \mathrm{~cm}\right)$ above which there is a sharp pH decrease from the bulk pH to the pH at the pit mouth $(\mathrm{pH}=5)$. This critical radius does not exist for a solution of $\mathrm{pH} 7$. This indicates that in basic solutions, pits greater than $10^{-6} \mathrm{~cm}$ in radius will exhibit a tendency to spread rather than deepen. 


\section{INTRODUCTION}

\subsection{Background and Motivation}

Federal regulations require that containers designed for radioactive waste disposal last 300 to 1000 years. The kinetic and mass transfer characteristics of iron and steel corrosion must be understood in order to design accurately disposal containers for this application. Pitting, a form of localized corrosion, is one of the most common causes of fallure in contalnment vessels, elther directly as a result of perforation of the metal or Indirectly as a precursor of stress corrosion cracking. The corrosion of a metal surface is thermodynamically favorable, but often does not occur due to the formation of a thin film of metal oxide on the metal surface. This phenomenon is known as passivation. The passivity of a metal is affected by the local $\mathrm{pH}$ and the metal's potential at this $\mathrm{pH}$ (Pourbaix, 1974). Therefore, the effect of $\mathrm{pH}$ on $\mathrm{pit}$ growth needs to be well understood before the performance of a contalnment vessel can be accurately predicted. Although a great deal of work has been done measuring the corrosion rates of iron and steel subjected to a variety of environments, little information is avallable on the variation of $\mathrm{pH}$ in a corroding pit and the surrounding metal.

Pitting corrosion occurs via the formation of a localized galvanic cell on the surface of the metal. When elemental iron is oxidized in the pit (the anode), electrons are released which move through the metal and react with water and oxygen at the metal surface surrounding the pit (the cathode) to form hydroxide Ions (Figure 2-1):

$$
\begin{aligned}
& \text { Anodic Reaction: } 2 \mathrm{Fe}=2 \mathrm{Fe}^{++}+4 \mathrm{e}^{-} \\
& \text {Cathodic Reaction: } \mathrm{O}_{2}+2 \mathrm{H}_{2} \mathrm{O}+4 \mathrm{e}^{-} \longrightarrow 4 \mathrm{OH}^{-}
\end{aligned}
$$

Thus, anodic ilssolution of metal (oxidation) and cathodic reduction of oxygen occur simultaneously with the resultant current being proportional to the rate of metal dissolution. The rate of reaction (2-2) depends on the concentration of oxygen present at the cathode. Conditions may arise where the current is limfted by the diffusion of oxygen to the electrode surface. The reduction of hydrogen fons can take place at the cathode.

$$
2 \mathrm{H}^{+}+2 \mathrm{e}^{-} \longrightarrow \mathrm{H}_{2}
$$

The ferrous lons may either: (a) form complexes with the anions that migrate into the pit, (b) undergo hydrolysis:

$$
\begin{gathered}
\mathrm{Fe}^{++}+\mathrm{H}_{2} \mathrm{O} \mathrm{Fe}(\mathrm{OH})^{+}+\mathrm{H}^{+} \\
\mathrm{Fe}(\mathrm{OH})^{+}+\mathrm{H}_{2} \mathrm{O} \mathrm{Fe}(\mathrm{OH})_{2}+\mathrm{H}^{+}
\end{gathered}
$$

or (c) if oxygen is present, oxidize to form ferric lons:

$$
4 \mathrm{Fe}^{++}+\mathrm{O}_{2}+2 \mathrm{H}_{2} \mathrm{O}=4 \mathrm{Fe}^{+++}+4 \mathrm{OH}^{-}
$$


PIT INITIATION AND GROWTH

Bulk Electrolyte

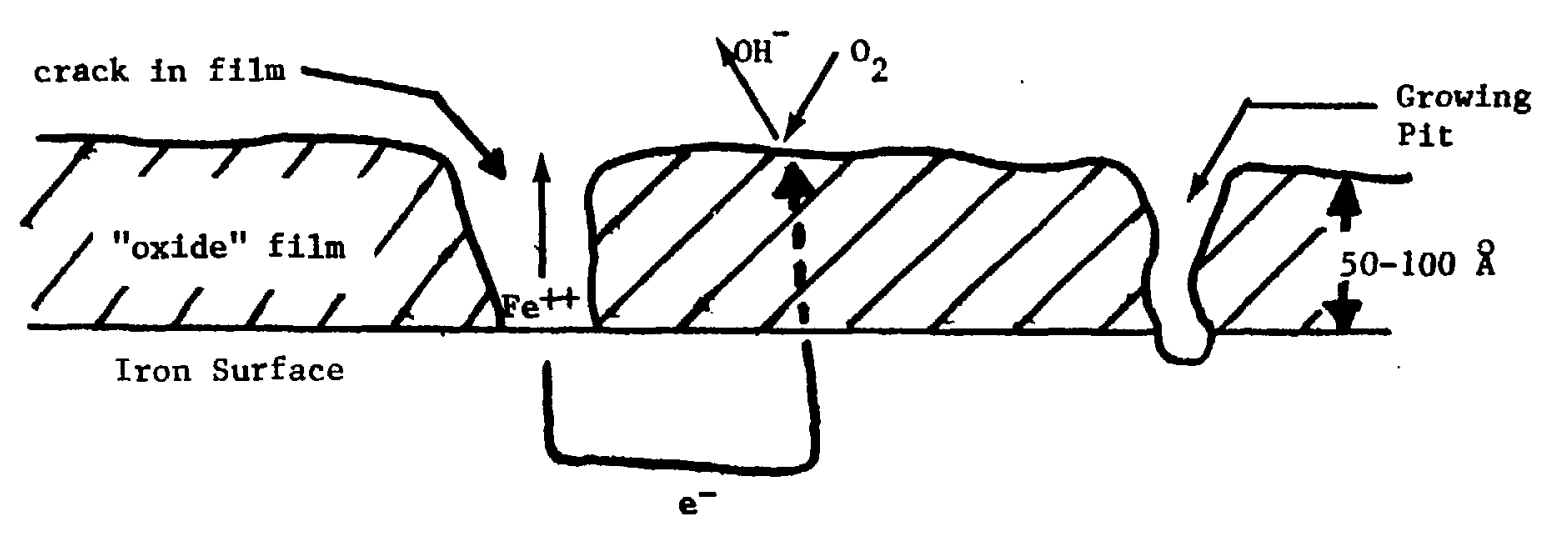


which can combine with hydroxide lons to precipitate ferric hydroxide:

$$
\mathrm{Fe}^{+++}+3 \mathrm{OH}^{-} \rightarrow \mathrm{Fe}(\mathrm{OH})_{3} \downarrow
$$

The increase in $\mathrm{H}^{+}$concentration from the hydrolysis reactions hinders the formation of a passive film at the pit bottom at high current densities, thus enhancing the rate of pit deepening. The $\mathrm{pH}$ at the bottor of the pit can be as 1 ow as 1.5 (Sedriks, 1979). On the other hand, the pH at the cathode outside the pit will increase due to the production of $\mathrm{OH}^{-}$lons by Reaction $(2-2)$. Thus, a pH gradient must exist between the mouth of the pit and the cathodic region. If the $\mathrm{pH}$ at the metal surface adjacent to the pit mouth is below a "critical" value, the passive film around the pit will dissolve and the pit will widen.

Galvele (1976) developed a model to predict pH changes within a onedimensional pit as a function of pit depth, he also explained the effect of bulk solution $\mathrm{pH}$ on the critical potential. He found the critical pitting potential of bivalent metals to be $\mathrm{pH}$ independent up to $\mathrm{pH} 9$, but $\mathrm{pH}$ dependent for higher pH values. Galvele (1981) later extended the model to account for the full hydrolysis of metal ions as they diffuse through the solution. Since the $\mathrm{pH}$ affects the range of potentials over which corrosion can occur, a model needs to be developed to predict variations in $\mathrm{pH}$ outside the pit and the relationship between $\mathrm{pH}$ and pitting potential.

\subsection{Objectires and Method of Approach}

The objective of this project was to determine the influence of $\mathrm{pH}$ changes in unbuffered chloride and sulfate solutions on the localized corrosion of iron.

To meet this objective we constructed two one-dimensional artificlal pit apparatuses each with a reference electrode, a pH probe, and an auxiliary electrode to simulate changes in the dissolution rate within actual iron pits. The pH of unbuffered, deoxygenated chloride and sulfate solutions was measured at room temperature as a function of current density, bulk anton concentration, and height above the pit bottom.

In order to explain the experimentally observed pH behavior, a model was developed that incorporates the transport of lons in and around a one-dimensional pit and predicts pH profiles in and around a pit from bulk conditions, pit dimensions and current densities. A comparison of predicted pH profiles in the pit with experimental data was made to establish the validity of the mode 1. The model was also compared to the model derived by Galvele (1976). The $\mathrm{pH}$ profiles outside the pit were predicted and the critical pH for depassivation was determined for pits of varying radil. 


\section{THEORY OF PITTING CORROSION}

\subsection{Passivity of Metals}

A passive metal is one for which corrosion is thermodynamically favorable but nevertheless corrodes at a very low rate. Metals are made passive by exposure to passivation environments such as iron exposed to chromate or nitrite solutions or by anodic polarization at sufficiently high current densities (Uh11g, 1971). The phenomenon of passlvation is belfeved to be due to the formation of an oxide film on the surface of the metal. This film is observed at potentials above what is called the passivation potential.

The thermodynamically predicted stabllity of solid and aqueous compounds as a function of $\mathrm{pH}$ and potential can be determined from a Pourbaix diagran for the metal of interest (Pourbalx, 1974). A Pourbaix diagram defines regions in which a given compound is in equilibrium with an aqueous solution of an arbitrarily small concentration ( $10^{-6}$ molar) of a metal lon. The Pourbaix diagram for iron is shown in Figure 3-1. The horizontal 1 ine at -620 $\mathrm{mV}$ separating $\mathrm{Fe}$ and $\mathrm{Fe}^{++}$indicates that along this line, no dependence of $\mathrm{pH}$ is observed.

$$
\mathrm{Fe}-\rightarrow \mathrm{Fe}^{++}+2 \mathrm{e}^{-}
$$

The lines in Figure 3-1 marked 0 , and -6 indicate the 109 of the trace iron molar concentration. At each of these concentrations, the critical pH is defined as the $\mathrm{pH}$ at which the ferrous lon and solid $\mathrm{Fe}(\mathrm{OH})_{2}$ reglons meet. Below this $\mathrm{pH}, \mathrm{Fe}(\mathrm{OH})_{2}$ will dissolve. Assuming that the passive layer is composed of $\mathrm{Fe}(\mathrm{OH})_{2}$, this critical $\mathrm{pH}$ leads to a criterion for depassivation. The ferrous ion concentration adjacent to the metal is determined by the amount of metal which has dissolved and how fast this diffuses away. Since this criterion is dependent on the geometry of the corroding metal and the surrounding electrolyte, an arbitrary criterion is used: a ferrous ion concentration of $10^{-6}$ mole/1 and higher implies "considerable" corrosion (a few milligrams of iron per liter of solution). At this concentration, the critical pH 1s approximately 9.5. It should be noted that for conditions of restricted ferrous ion diffusion, e.g・, pits, a considerably higher ferrous Ion concentration may occur in the solution at the bottom of the pit. In this case, the critical pH may be as low as 6.5 (Figure 3-1).

The diagrans do not describe the kinetics of any reaction; therefor, the rate of formation of a passivating film is not predicted - its formation is only said to be possible or impossible.

\subsection{Initiation of Pitting and Pit Growth}

At anodic potentials above the pitting potential, the current density inside a crack in the passive layer $18 \mathrm{hlgh}$ enough to cause the dissolution of iron by the anodic reaction:

$$
2 \mathrm{Fe} \longrightarrow 2 \mathrm{Fe}^{++}+4 \mathrm{e}^{-}
$$




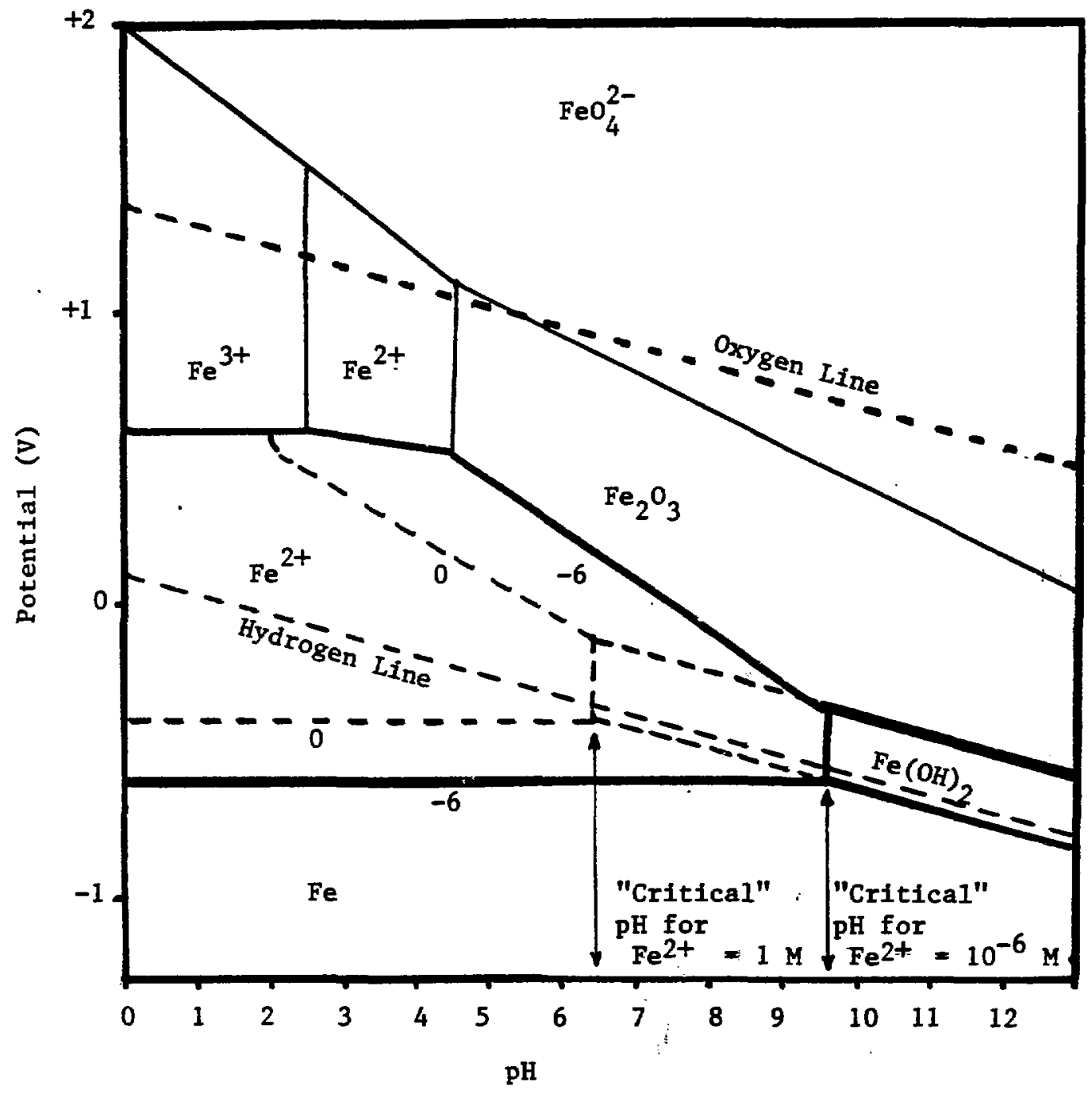

MASSACHUSETTS INSTITUTE OF TECHNOLOGY SCHOOL OF CHEMICAL ENGINEEAING PAACTICE 
This initiates pitting corrosion. Electrons must be consumed in a cathodic region of the metal,

$$
\mathrm{O}_{2}+2 \mathrm{H}_{2} \mathrm{O}+4 \mathrm{e}^{-}--\rightarrow 4 \mathrm{OH}^{-}
$$

producing hydroxide lons or, if oxygen is not present or cannot diffuse fast enough to the metal surface, hydrogen gas is evolved:

$$
4 \mathrm{H}^{+}+4 \mathrm{e}^{-}-\rightarrow 2 \mathrm{H}_{2}
$$

Both cathudic reactions result in a localized increase in pH outside the pit, due to the generation of hydroxide lons in Reaction (3-2), or due to the depletion of hydrogen ions in Reaction (3-3).

The ferrous ions produced by Reaction (3-1) rapidly hydrolyze within the pit:

$$
\mathrm{Fe}^{++}+\mathrm{H}_{2} \mathrm{O} \stackrel{\mathrm{K}_{1}}{\longrightarrow} \mathrm{Fe}(\mathrm{OH})^{+}+\mathrm{H}^{+}
$$

where

$$
\mathrm{K}_{1}=\left[\mathrm{Fe}(\mathrm{OH})^{+}\right]\left[\mathrm{H}^{+}\right] /\left[\mathrm{Fe}^{++}\right]
$$

$$
\mathrm{Fe}(\mathrm{OH})^{+}+\mathrm{H}_{2} \mathrm{O} \stackrel{\mathrm{K}_{2}}{\longrightarrow} \mathrm{Fe}(\mathrm{OH})_{2}+\mathrm{H}^{+}
$$

where

$$
\mathrm{K}_{2}=\left[\mathrm{Fe}(\mathrm{OH})_{2}\right]\left[\mathrm{H}^{+}\right] /\left[\mathrm{Fe}(\mathrm{OH})^{+}\right]
$$

The equilibrium constants for Reactions (3-5) and. (3-6) are large enough (on the o:der of $10^{-7}$ mole/1 to $10^{-11}$ mole/1) to significantly increase the;concentration of $\mathrm{H}^{+}$and result in reductions in $\mathrm{pH}$ at the bottom of a pit.

The passive film on a metal's surface will dissolve at pH's below a "critical" $\mathrm{pH}$. This $\mathrm{pH}$ is determined by the concentration of $\mathrm{H}^{+}$at which the passivating oxide film is in equilibrium with a solution containing traces of the metal lons. The "critical" pH for iron is calculated from the Pourbaix potential-pH diagran for iron (Figure 3-1) to be 9.5 (at a ferrous ion concentration of $10^{-6}$ mole/1). According to a transport model developed by Galvele (1976), a reduction in $\mathrm{pH}$ below this value will occur at a value for ( $\mathrm{X}$ ) ( 1 ) of $10^{-6} \mathrm{~A} / \mathrm{cm}$, where $X$ is the pit depth (in $\mathrm{cm}$ ) and $i$ is the current density (in $\mathrm{A} / \mathrm{cm}^{2}$ ). Since typical current densities at pit initiation are on the order of $1 \mathrm{~A} / \mathrm{cm}^{2}$, the necessary acidification can be obtained at a pit depth of $10^{-6} \mathrm{~cm}$. This means that a crack in the passivating oxide film would yleld a diffusion path long enough to reach the critical pH. If such cracks are present, the application of a potential high enough to reach a current density of a $1 \mathrm{~A} / \mathrm{cm}^{2}$ would propagate pitting.

Once pitting has been initiated, the dissolution of metal in the pit continues since the resultant acidification due to hydrolysis reactions prevents repassivation. Inftially, the rate of metal dissolution is controlled by the kinetics at the metal/solution interface. However, if the rate of diffusion of metal lons into the bulk solution is slow, the concentration of metal ions 
increases at the dissolving surface until saturation is reached; at this time the metal salt $\left(e .8 ., \mathrm{FeCl}_{2} \cdot \mathrm{HH}_{2} \mathrm{O}\right)$ precipitates on the pit surface. The rate of dissolution is then controlled by the diffusion of the salt out of the pit and becomes independent of the pit potential. As the pit deepens, the current decreases gradually due to increasing resistance through the pit until corrosion eventually ceases.

In addition to deepening the pit, the acidification extends beyond the pit mouth and dissolves the external passive layer. The exposed surface is subject to corrosion and the pit gradually widens. However, in this case, the increase in pit diameter leads to a reduction in current density until corrosion ceases. The type of pit formed (deep, aarrow pits or wide, shallow pits) is dependent on the system under consideration. Iron is known to form deep, narrow pits in the presence of chloride solutions while forming shallow, wide pits in the presence of sulfate solutions (Isaacs, 1986).

\subsection{Factors Affecting Pitting}

\subsubsection{Anion Concentration}

Galvele (1976) discounts the hypothesis that chloride-ion buildup at the metal-solution interface penetrates the oxide film and initiates pitting (Uhlig, 1971). He instead states that the concentration of $\mathrm{Cl}^{-}$present in the bulk solution affects the potential difference between the solution at the bottom of the pit and the bulk solution. This potential difference is given by:

$$
\phi_{1}-\phi_{0}=(\mathrm{RT} / \mathrm{F}) \ln \mathrm{C}_{0}
$$

where $\phi_{i}-\phi_{0}$ is the potential difference and $C_{0}$ is the bulk concentration of the electrolyte. He notes that the potential difference is required in order to cause an increase in $\mathrm{Cl}^{-}$concentration at the anode. This $\mathrm{Cl}^{-}$buildup is polarization effect due to high current densities. Galvele concludes that the actual pitting potential is not affected by anion concentration for iron, aluhinum, nickel, and other metals, but rather it is the potential measured in the bulk which is affected.

\subsubsection{Currert Density}

The oxide film on a passive metal is not a perfect layer; it suffers continuous breaks, thus exposing bare metal to the solution. The current densities in these fissures are a function of the electrode potential. High rates of iron dissolution result in a local decrease in $\mathrm{pH}$ via the hydrolysis reactions. The oxide film undergoes further dissolution if the $p H$ is below the critical pH for solubilization; thus, increased current densities result in more corrosion via pitting.

\subsection{3 $\mathrm{pH}$ of the Bulk Electrolyte}

A large increase in the $\mathrm{pH}$ of the bulk solution inhibits the pitting process. Galvele (1976) showed that increasing the bulk pH increases the current 
density required to achieve a pH decrease sufficient to maintain the solubilization of the passive layer. An increase of a pH unit in the bulk results in a ten-fold increase in the current density required for pit growth at a given size. If this current density cannot be achieved, the pitting process is inhibited.

\subsection{Measurement of $\mathrm{pH}$}

Measurements of $\mathrm{pH}$ were performed in two ways: with a flat-bottomed glass $\mathrm{pH}$ electrode containing a reference electrode, and with an antimony electrode and external saturated calomel electrode. The glass electrode is inherently more accurate than the antimony probe, but has a disadvantage in its large size ( $12 \mathrm{~mm}$ diameter). The diameter of the antimony probes was less than $0.5 \mathrm{~mm}$.

If $E_{1}$ and $E_{2}$ are the values of the potential of the pH probe with respect to the reference electrode when they are immersed in test solutions of $\mathrm{pH}_{1}$ and $\mathrm{pH}_{2}$, respectively, the $\mathrm{pH}$ probe response, $\mathrm{R}$ (in millivolts per $\mathrm{pH}$ unit) is given by

$$
R=\left(E_{1}-E_{2}\right) /\left(\mathrm{pH}_{1}-\mathrm{pH}_{2}\right)
$$

An ideal electrode would react to changes in hydrogen ion activity in exactly the same manner as the standard hydrogen gas electrode,

$$
\mathrm{E}_{1}-\mathrm{E}_{2}=(\mathrm{RT} / \mathrm{F})(1 \mathrm{n} 10)\left(\mathrm{pH}_{1}-\mathrm{pH}_{2}\right)
$$

Thus the Ideal $\mathrm{pH}$ response would be $(\mathrm{RT} / \mathrm{F})(\ln 10)$ volts per pH unit, i.e., $54.2 \mathrm{mV}$ at $0^{\circ} \mathrm{C}$, or $59.2 \mathrm{mV}$ at $25^{\circ} \mathrm{C}$. However, no glass electrode yet constructed has the theoretical response at all pH ranges (Wilscn, 1970).

The antimony probe also operates on the principle of potential difference measurement. A thin layer of antimonous oxide rapidly forms on the surface of an antimony sample when exposed to air. This oxidation-reduction reaction between antimony and antimonous oxide is the cause of the potential of the antimony electrode. The following electrochemical reaction occurs when an antimony electrode is placed in aqueous solution

$$
\mathrm{Sb}_{2} \mathrm{O}_{3}(\mathrm{~s})+6 \mathrm{H}^{+}+6 \mathrm{e}^{-} \rightleftharpoons 2 \mathrm{Sb}(\mathrm{s})+3 \mathrm{H}_{2} \mathrm{O}(1)
$$

oxygen is required to continually re-oxidize the antimony to antimonous oxide which is reduced by the above reaction. The potential of reaction (3-10) can be measured and compared to values obtained at a known $\mathrm{H}^{+}$concentration. However, the response of this probe varies with the condition of the metal, whether cast or electroplated, polished or etched (Wilson, 1970). As a result, antimony probes are only accurate to about $0.5 \mathrm{pH}$ unit and must be repeatedly calibrated in a series of standard buffers. 


\subsection{Modeling Ion Transport in Corroding Pits}

Galvele (1976) developed a pit model of the localized corrosion of metals, in which the metal lons $\left(\mathrm{Me}^{++}\right.$) hydrolyze inside the pits and the corrosion products are transported by diffusion. He predicted concentration profiles for the species $\mathrm{Me}^{++}, \mathrm{Me}(\mathrm{OH})^{+}$, and $\mathrm{H}^{+}$, as a function of current density and pit depth. The main reason for passivity breakdown was assumed to be the local acidification due to metal ion hydrolysis by the reaction:

$$
\mathrm{Me}^{++}+\mathrm{H}_{2} \mathrm{O} \longrightarrow \mathrm{Me}(\mathrm{OH})^{+}+\mathrm{H}^{+}
$$

The consequences of the additional hydrolysis step,

$$
\mathrm{Me}(\mathrm{OH})^{+}+\mathrm{H}_{2} \mathrm{O} \rightleftharpoons \mathrm{Me}(\mathrm{OH})_{2}(\mathrm{aq})+\mathrm{H}^{+}
$$

and hydroxide precipitation,



were studled in a later paper (Galvele, 1981). Galvele made several assumptions in his analysis. First, he assumed that the pit was cylindrical with a flat bottom, at which the anodic reaction occurs:

$$
\mathrm{Me} \longrightarrow \mathrm{Me}^{++}+2 \mathrm{e}^{-}
$$

The walls of the pit were assumed to be covered by a passivating film. This assumption allowed him to apply one-dimensional transport equations to the problem. Second, he assumed that the dissoclation took place in a sodiun salt solution of an aggressive anion. The $\mathrm{pH}$ of the bulk solution was a known constant, used as the boundary condition at the pit mouth. Third, the hydrolysis Reactions (4-1 and 4-2) were assumed to be very fast, and thus at equilibriun. The formation rate of polynuclear complexes was assumed to be very slow. The last and most important assumption is that the aggressive anion salt is concentrated enough to act as a supporting electrolyte. Therefore, the transport of the metal ion species by electromigration can be ignored (Neman, 1973) and only the diffusive terms remain in the transport equations.

Galvele's model predicts that significant $\mathrm{pH}$ changes can occur at the bottom of pits as small as $10^{-6} \mathrm{~cm}$ deep, based on a typical current density of $1 \mathrm{~A} / \mathrm{cm}^{2}$. Pits this small could easily be formed by small cracks in the oxide film. It has been shown that the concentration profiles inside a pit reach steady state quickly, on the order of mlcroseconds (Rosebrugh and Lash-Miller, 1910). In the system studied, the applied potential is related to the current density by Tafel's equation:

$$
E=a+b \log 1
$$

where $E$ is potential, 1 the current density, and $a$ and $b$ are empirical constants. The phenomenon of repassivation is explained by calculating the conditions for the formation of solid $\mathrm{Fe}(\mathrm{OH})_{2} \cdot$ Galvele calculated that the solid 
ferrous hydroxide is not formed when the $\mathrm{pH}$ of the bulk solution (i.e., outside the pit) is less than 9, thus the pit will grow at any value of current density, and hence, potential. This explains the experimental observation that there is no critical pitting potential below pH 9 (Alverez and Galvele, 1980). Above a $\mathrm{pH}$ of 9 , the pitting potential obeys an equation of the form,

$$
E=a+b \mathrm{pH}
$$

where $a$ and $b$ are the same constants as in (4-5) above.

\subsection{One-Dimensiona 1 Transport Outside a Corroding Pit}

The model developed in this report is based upon the one-dimensional transport equations developed by Galvele (1976 and 1981). However, Galvele only considered lonic transport and metal ion hydrolysis inside the corroding pit. He used the bulk solution composition as boundary conditions at the mouth of the pit. We hypothesized that concentration gradients exist around the mouth of the pit. The composition of solution in the pit is important in determining. If the oxide film near the pit mouth will dissolve, enlarging the pit. We extended Galvele's model to dezcribe the concentration profiles outside the pit, and used the conditions calculated at the mouth of the pit to recalculate the concentration profiles inside, the pit.

Two models are presented. One assumes that the cathodic reaction takes place at a distance sufficiently far away from the pit that any species produced or consumed there have no effect on the transport near the pit. The second model assumes that the cathodic reaction is the reduction of hydrogen lons to hydrogen gas, and that a constant flux of hydrogen is required to satisfy the material balance of the system of reactions. The location of the cathode need not be specified; the system of equations merely requires that enough hydrogen is supplied to a hemispherical cathode away from the mouth of the pit. Each model assumes that the pit mouth can be considered to be a point source of metal lons, that the metal ion hydrolysis reactions are at equilibrium, and that the bulk solution acts as a supporting electrolyte for the minor species as in Galvele's model.

\subsubsection{Model Derivation with no Cathodic Reaction}

The following species were assumed to be present in the solution outside the pit:

$$
\begin{array}{ll}
\text { 1. } & \mathrm{Fe}^{++} \\
\text {2. } & \mathrm{H}_{2} \mathrm{O} \\
\text { 3. } \mathrm{OH}^{-} \\
\text {4. } \mathrm{FeOH}^{+} \\
\text {5. } \mathrm{H}^{+} \\
\text {6. } \mathrm{Fe}(\mathrm{OH})_{2}
\end{array}
$$

The bulk electrolyte was assumed to be $1 \mathrm{~N} \mathrm{NaCl.}$ 
The geometry of the problem is shown in Figure 4-1. At any point, we assume that we are at steady-state; thus, the flux of the species containing Fe must be constant and equal to the generation rate. Thus,

Fe:

$$
J_{1}+J_{4}+J_{6}=i(I) / 2 F
$$

where

$$
\begin{aligned}
J_{\mathfrak{n}} & =\text { flux of species } \mathrm{n}, \mathrm{mol} / \mathrm{cm}^{2} \mathrm{~s} \\
i(r) & =\text { current density, } \mathrm{A} / \mathrm{cm}^{2} \\
r & =\text { distance from the } \mathrm{p} i \mathrm{t}, \mathrm{cm} \\
F & =\text { Faraday constant, } 96500 \mathrm{C} / \mathrm{eq}
\end{aligned}
$$

The flux of species containing $O$ and $H$ atoms should sum to zero at any point because there is no net generation or consumption of these atoms:

0:

$$
\begin{gathered}
\mathrm{J}_{2}+\mathrm{J}_{3}+\mathrm{J}_{4}+2 \mathrm{~J}_{6}=0 \\
2 \mathrm{~J}_{2}+\mathrm{J}_{3}+\mathrm{J}_{4}+\mathrm{J}_{5}+2 \mathrm{~J}_{6}=0
\end{gathered}
$$

It should be noted that the equation for conservation of charge:

$$
2 J_{1}-J_{3}+J_{4}+J_{5}=i(x) / F
$$

is a linear combination of the Equations (4-7), (4-8), and (4-9).

Eliminating $\mathrm{J}_{2}$ from equations (4-8) and (4-9) gives:

$$
J_{3}+J_{4}-J_{5}+2 J_{6}=0
$$

Ignoring transport due to the potential field (electromigration), the onedimensional flux equation is

$$
J_{n}=-D_{n}\left(d C_{n} / d x\right)
$$

where

$$
\begin{aligned}
& D_{n}=\text { diffusivity of species } \mathrm{n}, \mathrm{cm}^{2} / \mathrm{s} \\
& C_{n}=\text { concentration of species } \mathrm{n}, \mathrm{mol} / \mathrm{cm}^{2}
\end{aligned}
$$

Thus :

$$
D_{3}\left(d C_{3} / d r\right)+D_{4}\left(d C_{4} / d r\right)-D_{5}\left(d C_{5} / d r\right)+2 D_{6}\left(d C_{6} / d r\right)=0
$$

and with integration:

$$
D_{3} C_{3}+D_{4} C_{4}-D_{5} C_{5}+2 D_{6} C_{6}=k
$$

$k$ being an integration constant. If we let $r$ go to infinity, $c_{4}$ and $\mathrm{C}_{6}$ go to zero, therefore,

$$
k=D_{3} C_{3}{ }^{\circ}-D_{5} C_{5}{ }^{\circ}
$$




\section{Bulk Solution (1 N NaCl)}

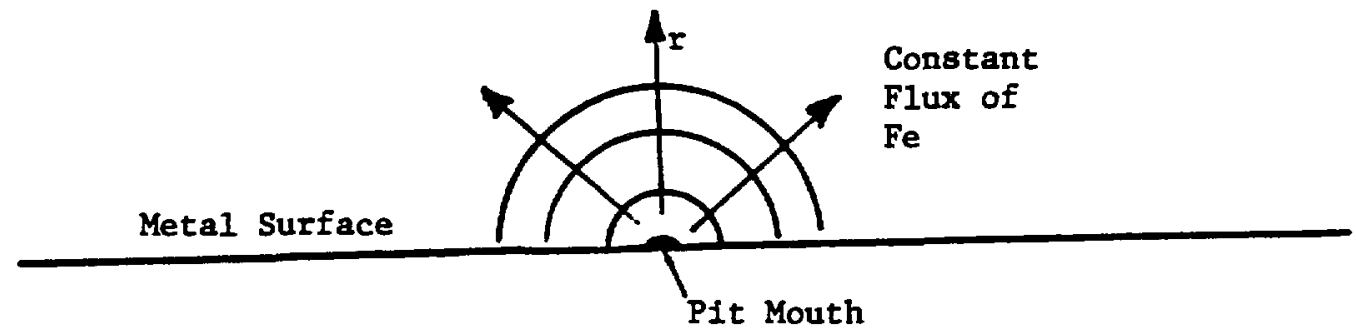

a) No Cathodic Reaction

Bulk Solution ( $1 \mathrm{~N} \mathrm{NaCl}$ )

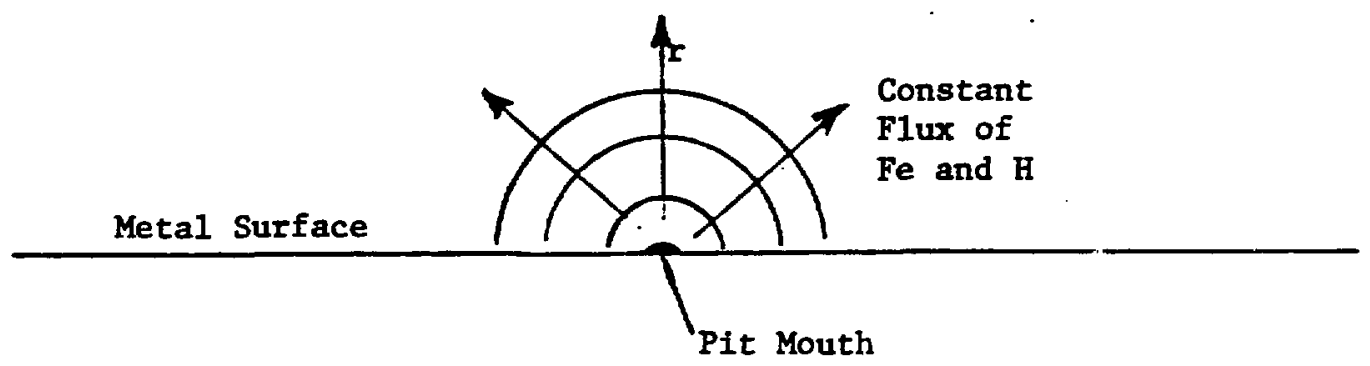

b) Hydrogen Reduction at Cathode

\begin{tabular}{|l|r|r|r|}
\hline DATE & DNAWN OY & FLLE NO \\
R-3-86 & RTH & FIT/BNL-86-6 & $4-1$ \\
\hline
\end{tabular}


where

$$
\begin{aligned}
& \mathrm{C}_{3}{ }^{\circ}=\text { bulk concentration of } \mathrm{OH}^{-} \\
& \mathrm{C}_{5}{ }^{\circ}=\text { bulk concentration of } \mathrm{H}^{+}
\end{aligned}
$$

We have expressions for $C_{4}$ and $C_{6}$ om terms of $C_{1}$ and $C_{5}$ in the equilibrium constants for the hydrolysis Reactions (4-1) and (4-2). The expressions are:

$$
\begin{aligned}
& c_{3}=k_{w} / c_{5} \\
& c_{4}=k_{1} k_{w} c_{1} / c_{5} \\
& c_{6}=k_{2} k_{w}{ }^{2} c_{1} / c_{5}{ }^{2}
\end{aligned}
$$

where

$$
\begin{aligned}
& K_{w}=\text { dissociation constant of water } \\
& K_{1}=\text { equilibrium constant of Reaction }(4-1) \\
& K_{2}=\text { equilibrium constant of Reaction }(4-2)
\end{aligned}
$$

If we let

$$
\begin{aligned}
& \mathrm{f}_{3}\left(c_{5}\right)=k_{w} / c_{5} \\
& f_{4}\left(c_{5}\right)=k_{1} K_{w} / c_{5} \\
& f_{6}\left(c_{5}\right)=k_{2} k_{w}{ }^{2} / c_{5}{ }^{2}
\end{aligned}
$$

then we can write:

$$
\begin{aligned}
c_{3} & =f_{3} \\
c_{4} & =c_{1} f_{4} \\
c_{6} & =c_{1} f_{6}
\end{aligned}
$$

Substituting (4-22), (4-23), and (4-24) into (4-25) and solving for $C_{1}$ in terms of $\mathrm{C}_{5} \mathrm{gives:}$

$$
c_{1}=\frac{D_{5} C_{5}-D_{3} f_{3}+k}{D_{4} f_{4}+2 D_{6} f_{6}}
$$

Since the current density ( $I$ ) is the current (I) divided by the area, for a hemisphere:

$$
\begin{gathered}
A(r)=2 \pi r^{2} \\
I=I / A(r)=I /\left(2 \pi r^{2}\right)
\end{gathered}
$$


Substituting equation (4-12) and (4-27) into equation (4-7) yields:

$$
D_{1}\left(d C_{1} / d r\right)+D_{4}\left(d C_{4} / d r\right)+D_{6}\left(d C_{6} / d r\right)=-I /\left(4 \pi F r^{2}\right)
$$

Integrating,

$$
D_{1} C_{1}+D_{4} C_{4}+D_{6} C_{6}=I /(4 \pi F r)+k^{\prime}
$$

with $C_{1}, C_{4}, C_{6}$ going to zero as $r$ goes to infinity. Thus $k$ is zero. Substituting (4-23) and (4-24) into (4-29) and rearranging,

$$
r=I /\left[4 \pi F C_{1}\left(D_{1}+D_{4} f_{4}+D_{6} f_{6}\right)\right]
$$

To calculate $r$, choose a value of $C_{5}$, $1 . e ., p H$, calculate $C_{1}$ from Equation (4-25), and substitute into Equation (4-30).

\subsubsection{Model Derivation with a Cathodic Resction}

In this model, it is assumed that the cathode consumes hydrogen according to the reaction:

$$
4 \mathrm{H}^{+}+4 \mathrm{e}^{-} \underset{2 \mathrm{H}_{2}}{\longrightarrow}
$$

The reduction of $\mathrm{O}_{2}$ at the cathode by

$$
\mathrm{O}_{2}+2 \mathrm{H}_{2} \mathrm{O}+4 \mathrm{e}^{-} \longrightarrow \mathrm{OH}^{-}
$$

is assumed to be small because it is limited by diffusion to the cathode. Thus, the flux equation for $H$ atoms is:

$$
2 J_{2}+J_{3}+J_{4}+J_{5}+2 H_{6}=I(r) / F
$$

while the equations for Fe and 0 atoms, (4-7) and (4-8), remalin the same. Eliminating $J_{2}$ from the Equations (4-8) and (4-33) yields

$$
J_{3}+J_{4}-J_{5}+2 J_{6}=-i(r) / F
$$

Substitution of equation (4-12) gives:

$$
D_{3}\left(d C_{3} / d r\right)+D_{4}\left(d C_{4} / d r\right)-D_{5}\left(d C_{5} / d r\right)+2 D_{6}\left(d C_{6} / d r\right)=1(r) / F \quad(4-35)
$$

Substituting equation (4-27) and Integrating:

$$
D_{3} C_{3}+D_{4} C_{4}-D_{5} C_{5}+2 D_{6} C_{6}=-I /(2 \pi F r)+k
$$

Since $C_{4}$ and $C_{5}$ go to zero as $r$ goes to infinity,

$$
k=D_{3} C_{3}{ }^{\circ}-D_{5} C_{5}{ }^{\circ}
$$


The equilibrium relations from which equations (4-22) to (4-24) were derived are still valid, so their substitution into equation (4-35) gives, with rearrangement:

$$
D_{3} C_{3}+D_{4} C_{1} f_{4}-D_{5} C_{5}+2 D_{6} C_{1} f_{6}=-I /(2 \pi F r)+k
$$

Equation (4-30) from the previous section is still valid, rearrangement of which yields:

$$
C_{1}=I /\left[2 \pi \mathrm{Fr}\left(D_{1}+D_{4} f_{4}+D_{6} f_{6}\right)\right]=h(r) g\left(C_{5}\right)
$$

where

$$
\begin{gathered}
h(r)=I / 2 \pi F r \\
g\left(C_{5}\right)=1 /\left[D_{1}+D_{4} f_{4}\left(C_{5}\right)+D_{6} f_{6}\left(C_{5}\right)\right]
\end{gathered}
$$

Substitution of Equation (4-39) into (4-38) gives:

$D_{3} f_{3}\left(C_{5}\right)+D_{4} f_{4}\left(C_{5}\right)_{g}\left(C_{5}\right) h(r)-D_{5} C_{5}+2 D_{6} f_{6}\left(C_{5}\right) g\left(C_{5}\right) h(r)=-h(r)+k$

Solving for $h(r)$ as a function of $C_{5}$ gives:

$$
\begin{aligned}
h(r) & =I /(2 \pi F r)=\frac{D_{5} C_{5}-D_{3} f_{3}+k}{1+D_{4} f_{4 g}+2 D_{6} f_{6 g}} \\
r & =\frac{I\left(1+D_{4} f_{4 g}+2 D_{6} f_{6 g}\right)}{2 \pi F\left(D_{5} C_{5}-D_{3} f_{3}+k\right)}=\frac{I f_{0}\left(C_{5}\right)}{2 \pi F} .
\end{aligned}
$$

Thus, given $C_{5}$, $r$ can be calculated from Equation (4-44) and the concentrations of the other species from Equations (4-16) to (4-18) and $(4-39)$.

\subsection{Model Predictions and Discussion}

\subsection{1 pH Profiles}

Values for the diffusivities and equilibrium constants $K_{1}, K_{2}, K_{w}$ (Table 4-1) can be substituted into the equations of the preceding section. As a result, we find that, at $\mathrm{pH}^{\prime} s$ less than 11 ,

$$
D_{4} f_{4} \gg \cdot D_{6} f_{6}
$$

at $\mathrm{pH}^{\prime} s$ less than 9 ,

$$
D_{1} \gg D_{4} f_{4}
$$

and at $\mathrm{pH}^{\prime} \mathrm{s}$ less than 7 ,

$$
D_{5} C_{5} \gg D_{3} f_{3}
$$




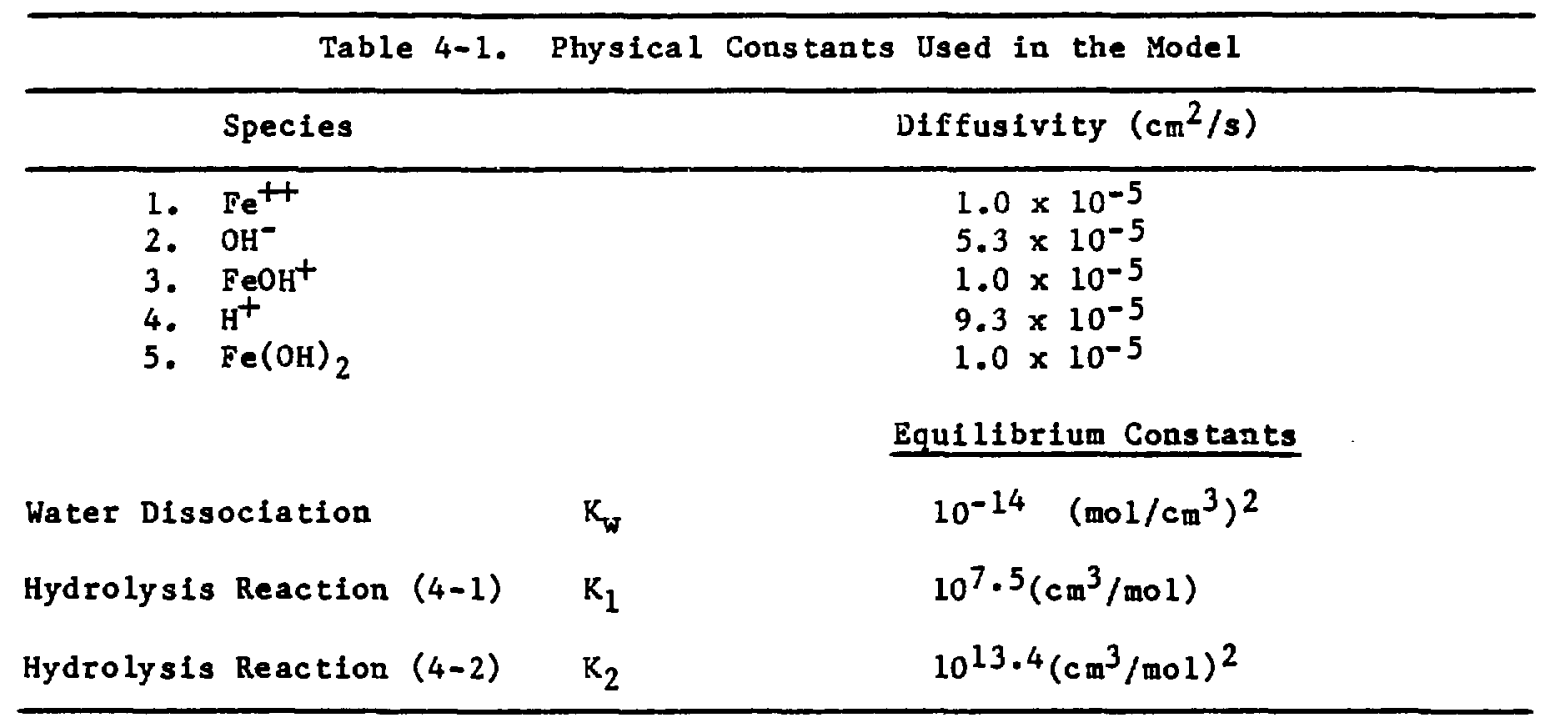

Thus at acidic conditions, the preceding simplifications can be made to Equations $(4-30)$ (Model I) and $(4-31$ ) (Model II):

$$
\begin{array}{cc}
r=I D_{4} K_{1} K_{w} /\left[4 \pi F D_{1} C_{5}\left(D_{5} C_{5}+k\right)\right] & \text { Model I } \\
r=I /\left[2 \pi F\left(D_{5} C_{5}+k\right)\right] & \text { Model II } \quad(4-48)
\end{array}
$$

If the bulk $\mathrm{pH}$ is near $7, k$ is small compared to $D_{5} C_{5}$, and the equations reduce to:

$$
\begin{array}{cc}
r=I D_{4} K_{1} K_{w} /\left[4 \pi F D_{1} D_{5} C_{5}{ }^{2}\right] & \text { Mode } 1 I \\
r=I /\left[2 \pi F D_{5} C_{5}\right] & \text { Model II }
\end{array}
$$

Since

$$
I=i_{0}\left(2 \pi r_{0}^{2}\right)
$$

where

$$
\begin{aligned}
& i_{0}=\text { current density at the pit mouth, } A / \mathrm{cm}^{2} \\
& r_{0}=\text { pit radius, } c m
\end{aligned}
$$


and since $C_{5}$ has units of mol/cm

$$
\begin{aligned}
\log \left(C_{5}\right) & =-(\mathrm{pH}+3) \\
\frac{r}{1_{0 v} r_{0}^{2}} & =\frac{D_{4} K_{1} K_{W}}{2 F_{v} D_{1} D_{5} C_{5}{ }^{2}} \quad \text { Model I } \\
\log \left(r / r_{0}\right)-\log \left(I_{0} r_{0}\right) & =\log \left(\frac{D_{4} K_{1} K_{W}}{2 F D_{1} D_{5}} 2(p H+3)\right. \\
\frac{r}{1_{0} r_{0}{ }^{2}} & =\frac{1}{F D_{5} C_{5}} \quad \text { Model II } \\
\log \left(r / r_{0}\right)-\log \left(1_{0} r_{0}\right) & =\log \left(1 / F D_{5}\right)-(p-53)
\end{aligned}
$$

\subsubsection{Conditions. at the Pit Mouth}

The $\mathrm{pH}$ and iron concentration at the mouth of the pit can be calculated for both models by solving equations (4-54) and (4-56) for pH at $r=r_{0}$. The bulk $\mathrm{pH}$ is assumed to be around 7, and the calculated $\mathrm{pH}^{\prime} \mathrm{s}$ must be less than 7 to be valid. For the first model (see Appendix 10.2):

$$
\mathrm{pH}_{0}=3.75-(1 / 2) \log 1_{0} r_{0}
$$

where

$$
\begin{aligned}
\mathrm{pH}_{0} & =\mathrm{pH} \text { at the mouth of the pit } \\
i_{0} & =\text { current density } \\
r_{0} & =\text { pit radius }
\end{aligned}
$$

For $1_{0} x_{0}$ values of $10^{-6}, 10^{-5}$, and $10^{-4} \mathrm{~A} / \mathrm{cm}$, the calculated pH ralues are $6.75,6.25$, and 5.75 respectively. To see if 6.75 ig $7 g$ enough for the calculation to be valid, let $1=1 \mathrm{~A} / \mathrm{cm}^{2}$, substitute $10^{-9}$. for $\mathrm{C}_{5}$ (in mol/ca ${ }^{3}$ ) in Equation (4-25), obtain $C_{1}$ and calculate $r$ from Equation (4-30). The calculated value for $r$ is $0.89 \times 10^{-6} \mathrm{~cm}$. $A \mathrm{pH}$ of 6.73 gives $r=1.0 \times$ $10^{-6} \mathrm{~cm}$.

Figure 4-2 shows the pH profiles vs. $\log \left(r / r_{0}\right)$ calculated by Model I for a bulk pH of 7 and 10 for $1_{0} x_{0}$ values of $10^{-4}$ to $10^{-6} \mathrm{~A} / \mathrm{cm}$. Since a current density of $1 \mathrm{~A} / \mathrm{cm}^{2}$ is typical of conditions at pit initiation (Galvele, 1976), these correspond to pit radii of $10^{-6}, 10^{-5}, 10^{-4} \mathrm{~cm}$ respectively. At a bulk pH of 7 , the slope in the linear region is $1 / 2$ as expected by inspection of Equation (4-54). Simplification of the equations for bulk 
pH PROFILES PREDICTED BY MODEL I (No Cathodic Reaction)

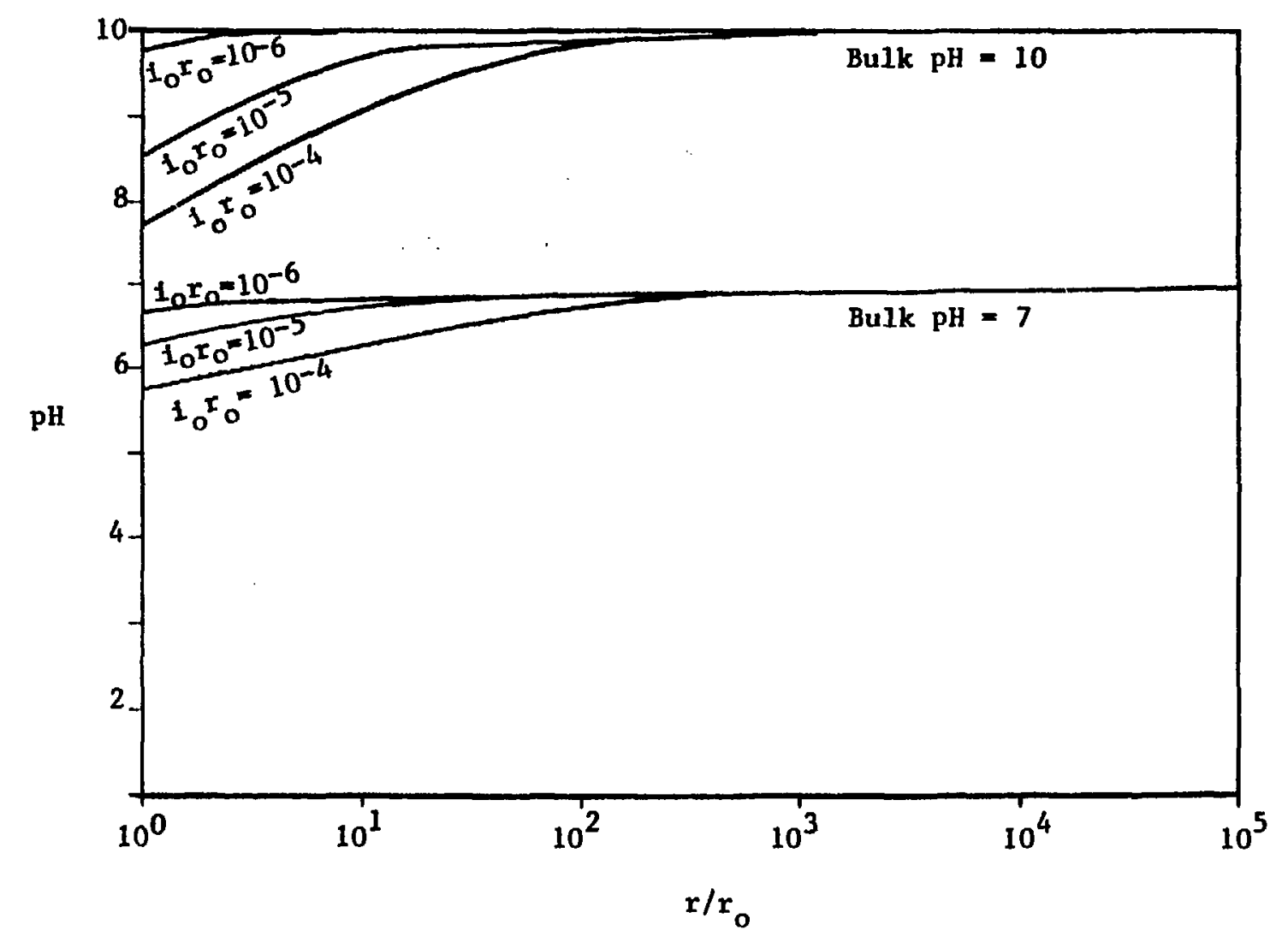


$\mathrm{pH}$ of 10 predicts a linear region of slope 1, as shown by Figure 4-2. At all conditions shown in the figure, the $\mathrm{pH}$ change at the pit mouth is at least $0.25 \mathrm{pH}$ unit, an amount that would be detectable if a probe small enough were used. The figure also shows that the bulk pH is achieved at 10 to 100 pit radii from the pit.

A similar algebraic manipulation (see Appendix 10.2) for the second model results in

$$
\mathrm{pH}_{0}=-2.29-\log i_{0} r_{0}
$$

Calculated $\mathrm{pH}$ values at the mouth of the pit are $3.71,2.71$, and 1.71 for the same values of $i_{0} I_{0}$ as above. These numbers are definitely low enough so that the simplifications are valid. Equation (4-56) predicts a region below $\mathrm{pH} 7$ where the slope of $\mathrm{pH}$ vs. $\log \left(\mathrm{r} / \mathrm{r}_{0}\right)$ will be unity. This is verified (Figure 4-3) for bulk pH's of both 7 and 10. The profiles for a bulk pH of 10 show a region where the pH changes dramatically. This is explained mathematically by observing that in this range of $\mathrm{pH}^{\prime} s, k$ is much larger in magnitude than $D_{5} C_{5}$ and $D_{3} C_{3}$, yielding a relatively constant value of $r$. Figure 4-3 shows that the sharp decline in $\mathrm{pH}$ only occurs above a value of $i_{0} r_{0}$ value of $10^{-6} \mathrm{~A} / \mathrm{cm}$. A linear region of slope $i$ is also seen, as predicted by Equation $(4-53)$.

Near the mouth of the pit, the assumption of a point source of Fe+t will break down. Therefore, the previous calculations for pit mouth conditions are approximate. The predicted concentrations of iron species for Model I (Table 4-2) and Model II (Table 4-3) should only be used to estimate the correct order of magnitude. Both models predict that the concentration of iron at the pit mouth will be proportional to the current density. If the concentrations could be measured in small pits of an accurately known size, the validity of the models presented here could be demonstrated. In our experimental apparatuses, we have physically separated the cathode from the artificial pit; therefore, only Model I (no cathode) will be used in the discussion of results. We can use Model I to obtain the approximate conditions at the mouth of the pit and use the results as boundary conditions with Galvele's nodel (1981). The previous calculations show that for large pit sizes, the error introduced by assuming bulk conditions at the pit mouth can be significant.

Table 4-2. Predicted Concentrations* of Iron Species at Pit Mouth for Model I

\begin{tabular}{clcc}
\hline $1_{0} \Gamma_{0}(\mathrm{~A} / \mathrm{cm})$ & {$\left[\mathrm{Fe}^{++}\right]$} & {$\left[\mathrm{FeOH}^{+}\right]$} & {$\left[\mathrm{Fe}(\mathrm{OH})_{2}\right]$} \\
\hline $10^{-6}$ & $5 \times 10^{-7}$ & $9 \times 10^{-10}$ & $4 \times 10^{-14}$ \\
$10^{-5}$ & $5 \times 10^{-6}$ & $3 \times 10^{-10}$ & $4 \times 10^{-14}$ \\
$10^{-4}$ & $5 \times 10^{-5}$ & $9 \times 10^{-9}$ & $4 \times 10^{-14}$
\end{tabular}

*in mole/ $/ \mathrm{cm}^{3}$ 
pH PROFILES PREDICTED BY MODEL II (Hydrogen Reduction at Cathode)

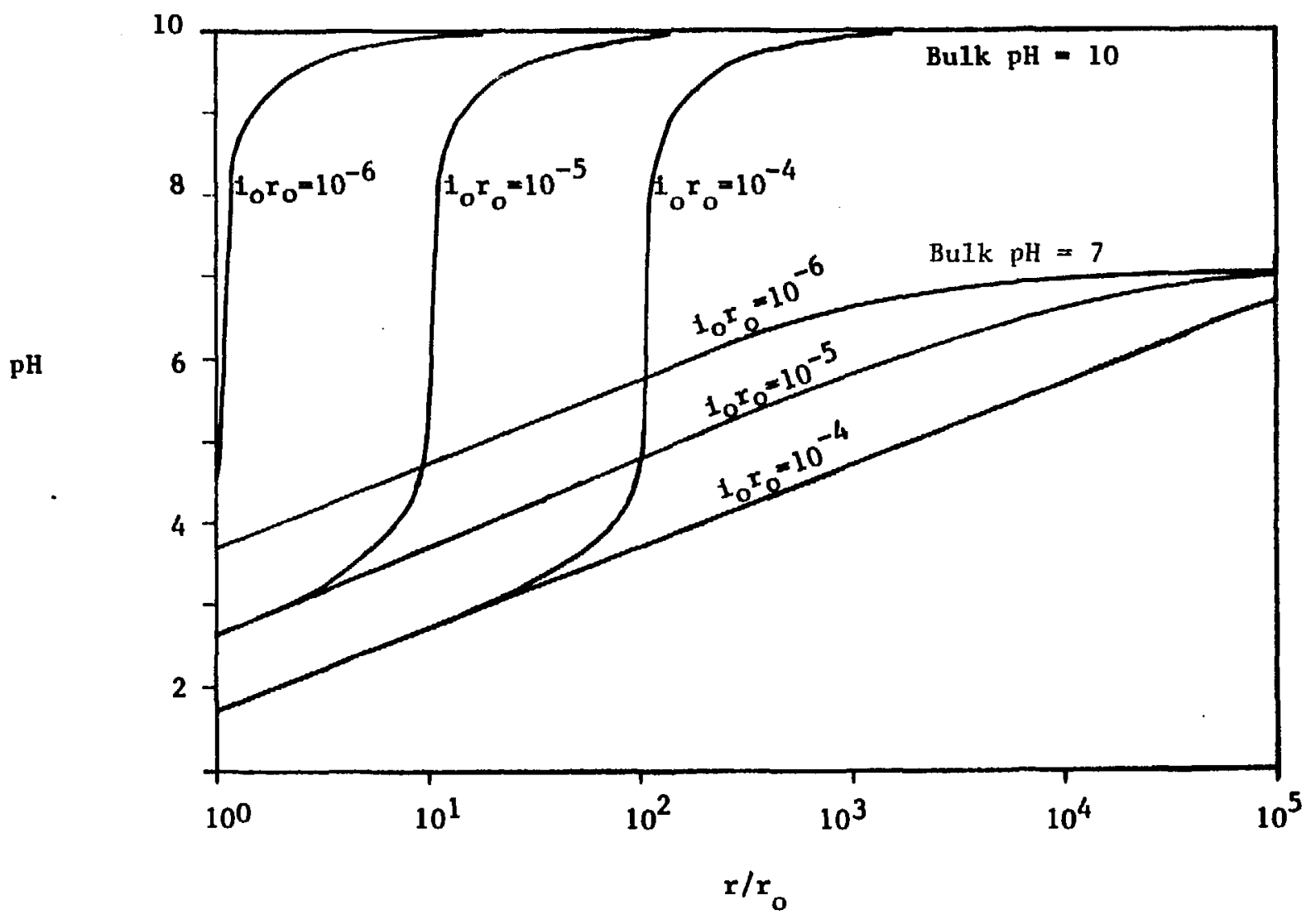


Table 4-3. Predicted Concentrations* of Iron Species at Pit Mouth for Model II

\begin{tabular}{clll}
\hline$i_{0} r_{0}(\mathrm{~A} / \mathrm{cm})$ & {$\left[\mathrm{Fe}^{++}\right]$} & {$\left[\mathrm{FeOH}^{+}\right]$} & {$\left[\mathrm{Fe}(\mathrm{OH})_{2}\right]$} \\
\hline $10^{-6}$ & $1 \times 10^{-6}$ & $2 \times 10^{-12}$ & $7 \times 10^{-20}$ \\
$10^{-5}$ & $1 \times 10^{-5}$ & $2 \times 10^{-12}$ & $7 \times 10^{-21}$ \\
$10^{-4}$ & $1 \times 10^{-4}$ & $2 \times 10^{-12}$ & $7 \times 10^{-22}$ \\
*in mol $/ \mathrm{cm}^{3}$ & & & \\
\hline
\end{tabular}




\subsection{Artificial Pit Apparatus}

A schematic diagram of an artificial pit apparatus is shown in Figure 5-1. Three electrodes are necessary for this apparatus: a metal working anode which simulates the corroding pit surface, a cathodic counter electrode which simulates the metal surrounding a real pit, and a reference electrode for the measurement of potential.

As discussed in Section 3, the pit solution becomes acidic due to metal fon hydrolysis and the solution surrounding the cathode becomes basic due to oxygen reduction. In order to reliably measure the local pH in the pit it is important to separate the anode and the cathode some distance in order to minimize the diffusion of $\mathrm{OH}^{-}$from the cathode solution to the pit solution. However, a large spatial separation would result in a large potential drop through the solution, causing the maximum obtainable current density to decrease due to voltage limitations. Some compromise must therefore be sought and the smallest separation possible without introducing $\mathrm{OH}^{-}$ions near the $\mathrm{pH}$ probe should be chosen.

In addition to the constraint of anode/cathode separation, the measurement of pH in the pit poses several problems. The measurement should ideally be non-invasive - the presence of any probe is certain to affect the concentration profiles in the pit. The size of the probe should be small in relation to the diameter of the pit. Several apparatuses were built in the present project, using different pit geometries and pH probes. Only the final two apparatuses are presented and discussed here. Problems encountered with other configuratons included high solution resistance, $\mathrm{OH}^{-}$diffusion into the $\mathrm{pit}$, and inadequate $\mathrm{pH}$ probes. The final two apparatus used different pH probes and had different pit geometries. The apparatuses are shown in Figures 5-2 and $5-3$.

Figure 5-2 shows the important dimensions and connections of the flatbottomed glass probe apparatus. The pit depth of about $40 \mathrm{~mm}$ was chosen to provide sufficient length to separate the region of acidity at the pit bottom from the cathode compartment. The $\mathrm{pH}$ probe was an Orion Research glass membrane electrode model 91-3600 with a flat bottom. The probe contained its own reference electrode and therefore did not require an external reference. The $\mathrm{pH}$ was recorded on a handheld Orion Research model 211 digital pH meter and an HP $7132 \mathrm{~A}$ Chart $S$ trip Recorder. The diameter of the probe was $12 \mathrm{~mm}$ and that of the pit $16 \mathrm{~mm}$. For most of the experimental runs the probe was located 1 mm from the electrode surface and therefore occupied $55 \%$ of the total pit rolume. Although this is probably far too large to enable point pH's to be measured, and certainly affected pH gradients, the apparatus was able to yield useful information on the acidification in the pit. The pH probe was secured in the center compartment with a Teflon sleeve. This arrangement ensured that the center compartment was sealed.

The working electrode (iron) was of diameter $16 \mathrm{~mm}$ with a connecting wire $30 \mathrm{~mm}$ long spot welded to it. The working electrode fitted into the 
SCHEMATIC ONE-DIMENSIONAL ARTIFICIAL PIT APPARATUS

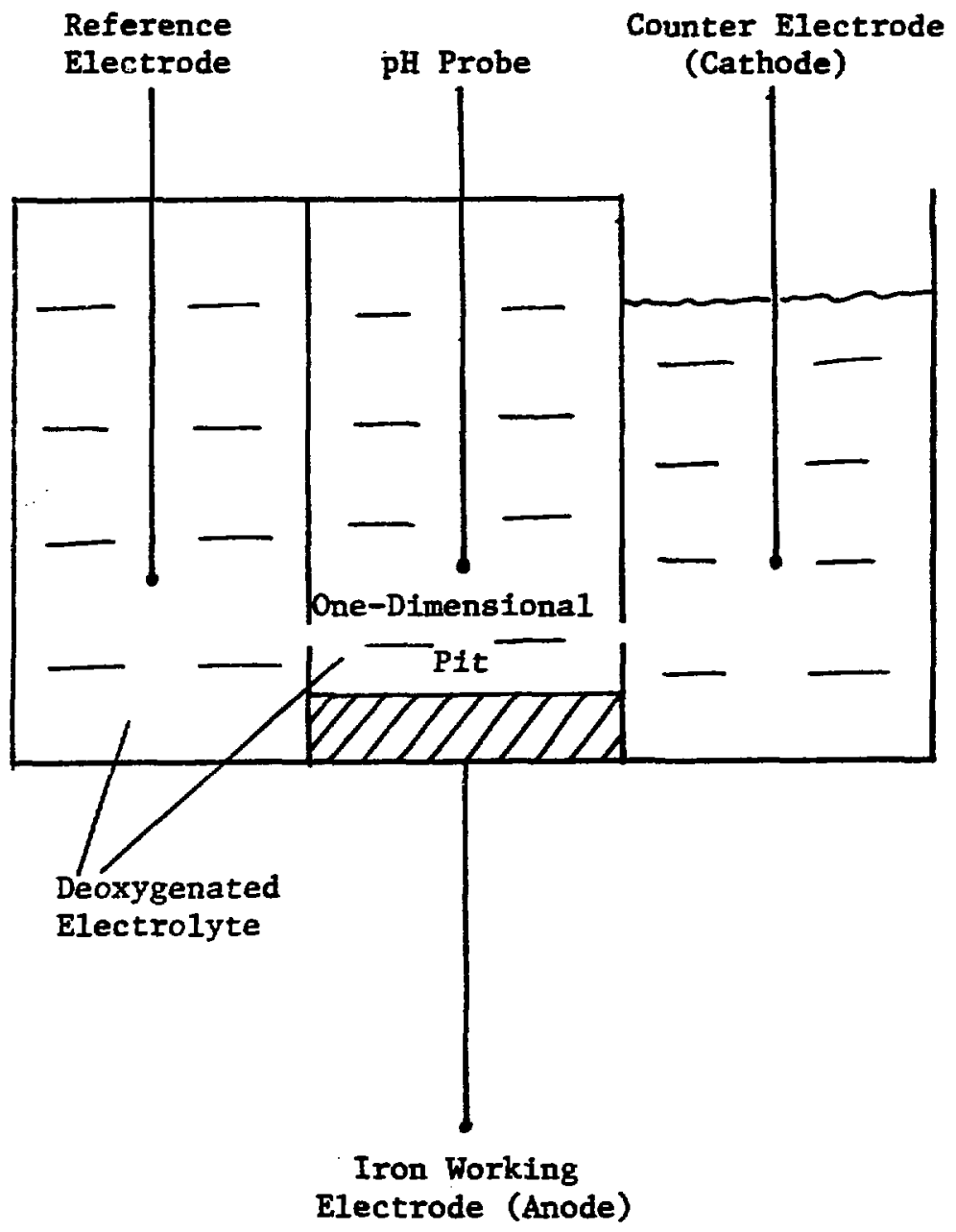

MASSACHUSETTS INSTITUTE OF TECHNOLOGY SCHOOL OF CHEMICAL ENGINEERING PRACTICE

\begin{tabular}{|l|l|l|l|}
\hline DATE & DRAWN BY & FLE NO. \\
MIT/BNL-86-6 & FIG. & $5-1$ \\
\hline
\end{tabular}




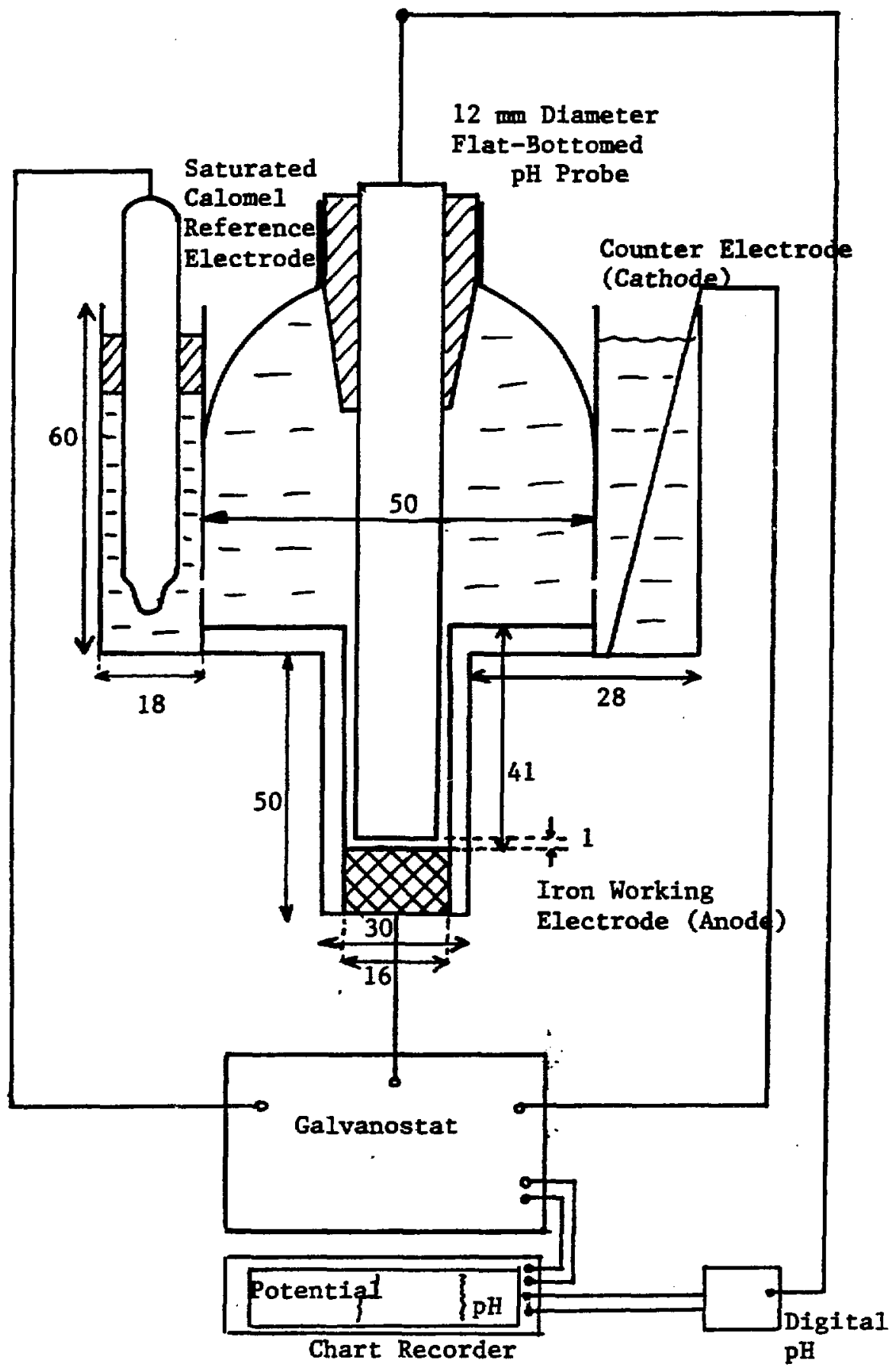

All Dimensions in mm 


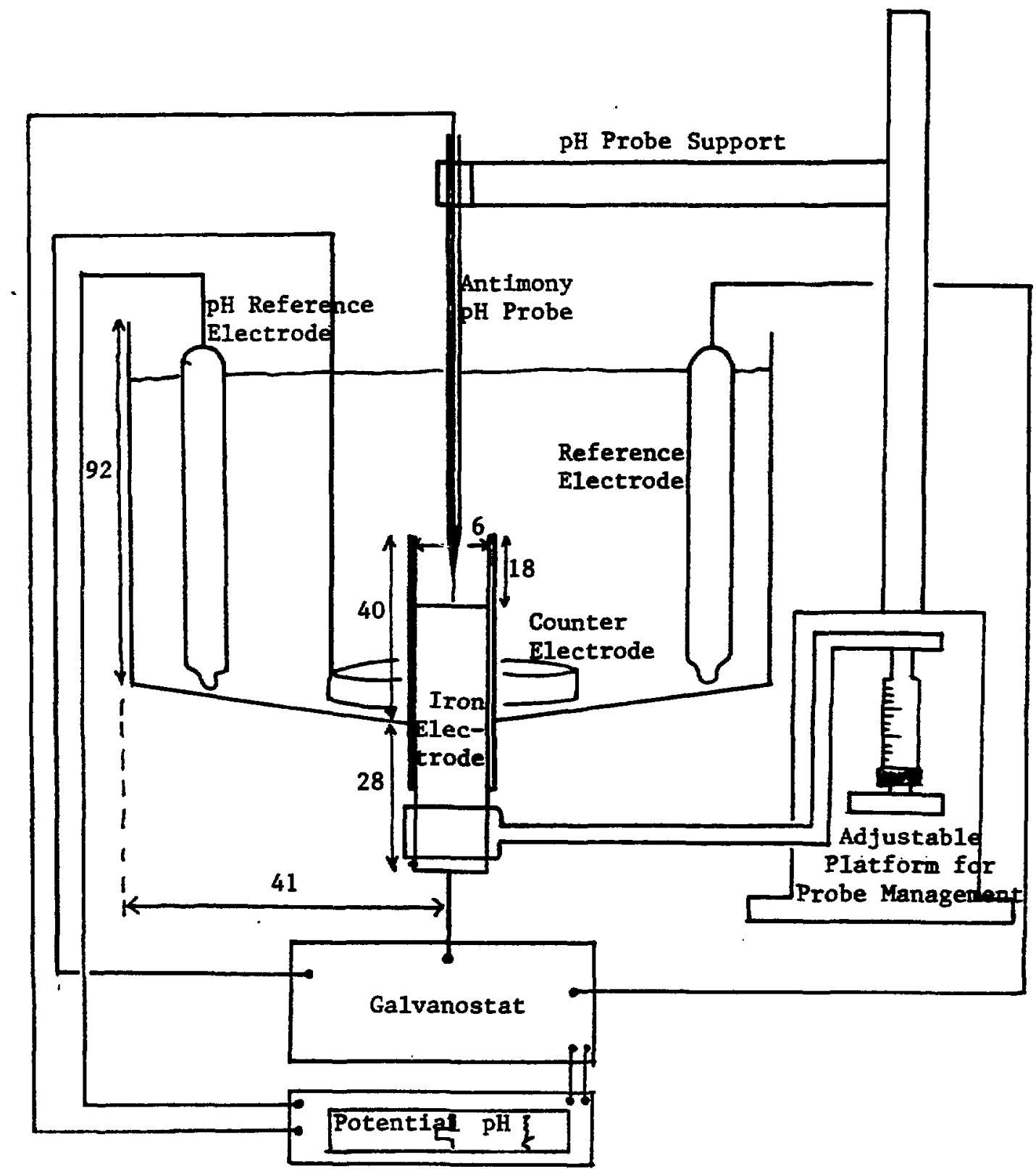

A11 Dimensions in mm

MASSACHUSETTS INSTITUTE OF TECHNOLOGY SCHOOL OF CHEMICAL ENGINEERING PRACTICE 
Teflon pit approximately $7 \mathrm{~mm}$ and was sealed with wax. The working electrode was connected to an EG\&G Princeton Applied Research model 362 scanning potentiostat, operated in the galvanostatic mode (constant current). The counter electrode consisted of a plate of nickel ( $5 \mathrm{~mm} \times 50 \mathrm{~mm} \times 0.2 \mathrm{~mm}$ ) of which 10-20 $\mathrm{mm}$ was submerged into the salt solution in the third compartment. The third compartment was not sealed and thereby permitted diffusion of $\mathrm{O}_{2}$ into solution. A small hole of $1 \mathrm{~mm}$ diameter located $4 \mathrm{~mm}$ above the pit mouth connected the center compartment to the side compartments. The counter electrode was also connected to the potentiostat.

The first compartment contained a Beckmann saturated calomel reference electrode model S31-27 which was secured by a Teflon ring at the mouth of the compartment. the solution in the first compartment was therefore sealed from the atmosphere. The tip of this electrode was 5 mm from the botton of the compartment. The reference electrode was connected to the electrometer of the potentiostat in order to monitor the potential of the anode.

Figure 5-3 shows the second apparatus used for measurement of pH profiles in the solution above the surface of an artificial pit. The pit consisted of a $6 \mathrm{~mm}$ rod of very pure iron housed in a $11 \mathrm{~mm}$ (OD) flexible transparent tube protruding $18 \mathrm{~mm}$ beyond the rod and therefore creating $a$ onedimensional artificial pit. The pit was located in a plexiglass cup of dianeter $82 \mathrm{~mm}$ and height $92 \mathrm{~mm}$ and sealed with wax. The iron rod (working electrode) was again connected to a EG\&G Princeton Applied Research model 362 scanning potentiostat. The cathode (counter electrode) was formed from a plate of nickel ( $5 \mathrm{~mm} \times 30 \mathrm{~mm} \times 0.5 \mathrm{~mm}$ ) bent into a circle. This electrode lay in the bottom of the cup external to the pit.

The reference electrode was inserted into the solution in the cup and held in place with an external clamp. Both reference and counter electrodes were connected to the potentiostat in the manner described previously. The salt solution covered the $p i t$ and was usually filled to within $5 \mathrm{~mm}$ of the top of the cup. The surface was not sealed.

The $\mathrm{pH}$ in the pit was measured with a miniature antimony electrode shown in Figure 5-4. These were constructed from a $2 \mathrm{~mm} O D$ ( $1 \mathrm{~mm}$ ID) glass tube filled with $5 \mathrm{~mm}$ of antimony beads at one end. The tip of the tube was heated and drawn out into a fine point. A $0.4 \mathrm{~mm}$ diameter copper wire was inserted into the molten antimony and served as the external connection. The dimensions of the probe used are shown in the diagram. Although a thinner tip could be obtained, (and is desirable so as not to disturb the profiles in the pit) it was observed that subsequent calibration of these extremely thin probes was erratic and that the the probes were not sturdy enough to make their use practical. A probe tip of $0.4 \mathrm{~mm}$ diameter was achieved. With the probe $1 \mathrm{~mm}$ from the surface of the artificial pit, approximately $4 \%$ of the pit volume was taken up by the probe (and only $2 \%$ of the area). The antimony probe therefore is capable (in principle) of measuring a "point" $\mathrm{pH}$ and $\mathrm{pH}$ profiles in an artificial pit. The probe required a reference electrode for its measurement of $\mathrm{pH}$ and therefore a second saturated calomel electrode was inserted into the solution. The probe was clamped vertically above the pit mouth and the apparatus clamped to a yertically movable platform. By 
ANTIMONY PH PROBE

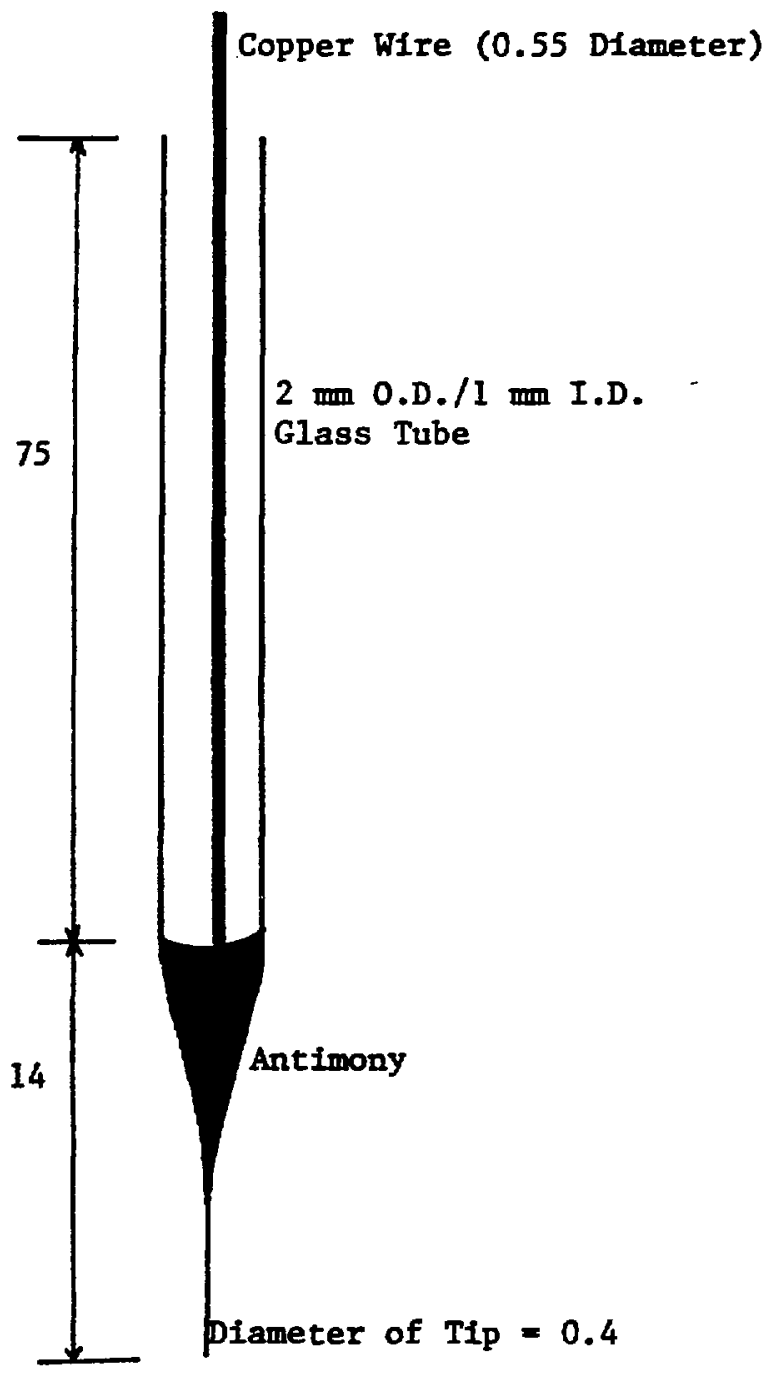

Al1 Dimensions in mm

MASSACHUSETTS INSTITUTE OF TECHNOLOGY SCHOOL OF CHEMICAL ENGIMEERING PRACTICE 
adjusting a micrometer screw gauge, the platform was moved up and down relative to the $\mathrm{pH}$ probe and therefore the $\mathrm{pH}$ could be measured at any distance above the height of the pit surface. The platform could be moved reproducibly to within $0.05 \mathrm{~mm}$. A light shined through the apparatus to facilitate visual adjustment of the probe position.

\subsection{Experimental Procedure}

\subsubsection{Measurement of $\mathrm{pH}$ and Potential with the Flat-Bottomed pH Probes}

To determine the lower limit of pH attainable in an artificial pit, the apparatus in Figure 5-2 was used with the iron electrode and the flat-bottomed probe located $1 \mathrm{~mm}$ above the surface of the iron electrode (or pit surface). The large nature of the $\mathrm{pH}$ probe relative to the pit implies that the dissolved Iron is essentlally contained in the solution between the pH probe bottom and the electrode surface. The measurement of $\mathrm{pH}$ therefore provides an "average" $\mathrm{pH}$ of a solution with a certain dissolved iron concentration determined by the amount of current passing through the electrolyte. The procedure used to measure the $\mathrm{pH}$ of the pit solution as a function of current density (and therefore iron concentration) is described.

A salt solution of known concentration was prepared - two salts, NaCl and $\mathrm{Na}_{2} \mathrm{SO}_{4}$ and two concentrations for each salt were used. This constituted the set of solutions: $2 \mathrm{M} \mathrm{NaCl}, 1 \mathrm{M} \mathrm{NaCl}, 1 \mathrm{M} \mathrm{Na} \mathrm{SO}_{4}$ and $0.5 \mathrm{M} \mathrm{Na}_{2} \mathrm{SO}_{4}$. Prior to filling the apparatus, the solutions were de-aerated by bubbling $\mathrm{N}_{2}$ gas through them for 1 hour. During this period the pH probe was calibrated in $s$ tandard buffer solutions of $\mathrm{pH} 2,4,7$ and 10 .

The apparatus was filled with the salt solution and the reference, $\mathrm{pH}$ and counter electrodes inserted in that order ensuring that no air bubbles were trapped in the reference and pH electrode compartments. The open circuit potential of the working electrode relative to the reference electrode was measured as was the pH. The predetermined current density was set on the galvanostat (values of $0.5 \mathrm{~mA} / \mathrm{cm}^{2}, 5.0 \mathrm{~mA} / \mathrm{cm}^{2}$ and $10 \mathrm{~mA} / \mathrm{cm}^{2}$ were used where possible) and the galvanostat and chart recorder switched on. The pH and potential were recorded as a function of time on the chart recorder. When no significant change in either $\mathrm{pH}$ or potential was noted (usually after about 2 hours), the current was stepped to its next value. It was noted that operation of the galvanostat affected the measurement of the $\mathrm{pH}$, therefore, the galvanostat was periodically switched off for about 5 seconds to obtafn the true $\mathrm{pH}$ reading from the digital pH meter. The pH record on the chart could therefore be calibrated in this manner. At the end of a run (determined by steady state approach at the last current value, usually 6 hours), the galvanostat was turned off, the apparatus emptfed and washed and the iron electrode prepared for the next experiment. This preparation was done by abrading the iron surface with silicon carbide paper no, 600 until no surface defects were visibly detected.

Frequently, $10 \mathrm{~mA} / \mathrm{cm}^{2}$ was not attainable since the solution resistance was too large and resulted in a voltage requirement larger than what the 
galvanostat could supply. In these cases, a lower current was used. These are indicated in the following chapter and discussed there.

\subsubsection{Attempt to Measure $\mathrm{pH}$ Profile In an Artificial Pit with the Flat- Bottomed Probes}

In an attempt to determine the gradient of $\mathrm{pH}$ in the artificial pit, three experimental runs were done in which the salt concentration (1N NaCl) and current density $\left(5 \mathrm{~mA} / \mathrm{cm}^{2}\right)$ were kept constant and the probe height changed. In the first experiment, the probe was located 1 mia from the pit surface and the experiment run in the manner described above at $5 \mathrm{~mA} / \mathrm{cm}^{2}$ for 2 hours at which steady state was achieved. In the second experiment, the probe was located $2 \mathrm{~mm}$ from the pit surface and once again a duration of 2 hours used. In the third experiment, the $\mathrm{pH}$ probe was located at the pit mouth (41 mm above the pit surface), left for most of the duration of the experiment ( 2 hours) and then very gradually moved into the pit with the pH being recorded at each point. In this manner a "profile" was obtained. The probe was moved up to the surface of the pit.

\subsubsection{Measurement of the $\mathrm{pH}$ Profile in an Artificial Pit with Antimony $\mathrm{pH}$ Micro-Probes}

A salt solution of fixed concentration was prepared (2N VaCl and $1 \mathrm{~N}$ $\mathrm{Na}_{2} \mathrm{SO}_{4}$ ) and de-aerated by bubbling $\mathrm{N}_{2}$ gas through for 1 hour. The antimony $\mathrm{pH}$ probes were extensively calibrated before use since several of these probes gave erratic results often exhibiting a long term drift in voltage response. Even with multiple calibrations with the same probe, sone error in reproducibllity was noted with an error of $0.2 \mathrm{pH}$ units at best.

The $\mathrm{pH}$ antimony electrode was located with its tip at the surface of the pit, the solution was added to the apparatus and the outer cup filled to within $5 \mathrm{~mm}$ of the brim. This was sufficient to cover the pit. The desired current was selected on the galvanostat, the galvanostat turned on and pH and potential recorded as a function of time. When steady state had been reached at this current density level, the $\mathrm{pH}$ probe was moved out of the pit firstly In increments of $0.63 \mathrm{~mm}$ (one revolution of the screw gauge) and after $7 \mathrm{~mm}$, in increments of $3 \mathrm{~mm}$. At each increment, the system was left for 5 minutes after which time a steady $\mathrm{pH}$ had been obtained. Once again, the operation of the galvanostat gave incorrect $\mathrm{pH}$ values which necessitated switching off the galvanostat briefly when $\mathrm{pH}$ measurements were taken. Once the probe had been moved out of the pit, it was moved in again in the same increments to establish the extent to which movement of the probe had affected the profiles in the pit. After the profile had been measured, the current density was changed and the procedure repeated. 


\section{EXPERIMENTAL RESULTS AND DISCUSSION}

\subsection{Flat-Bottomed Probe Apparatus}

The flat-bottomed probe apparatus was used to obtain values of the pH and potential in a one-dinensional artificial pit. However, due to the large size of the $\mathrm{pH}$ probe relative to the pit dianeter, the true pH profile in the pit could not be established and a semi-stagnant pocket of fluid is thought to exist in the space between the probe and the surface with diffusion of the ionic species up the annulus. The pH measured in the pit (typically the probe was $1 \mathrm{~mm}$ above the surface of the $\mathrm{p} i \mathrm{t}$ ) was therefore some "average" $\mathrm{pH}$ in this region due to the suppression of the true pH profile.

\section{1 .1 Potential and $\mathrm{pH}$ Changes}

Potential and $\mathrm{pH}$ were measured as functions of time in the apparatus for several values of current densities and salt concentrations. Typical profiles of $\mathrm{pH}$ and potential with time are presented in Figures 6-1 and 6-2. As expected, the $\mathrm{pH}$ of the solution decreased with time as more $\mathrm{Fe}^{++}$was dissolved. Although no true steady state was observed (as expected since ferrous ions are continously being added to the solution in the pit), the criteria used for changing the current was when the pH change was less than 0.05 unit/ $10 \mathrm{~min}$. The system was then considered to be in a quasi-steady state. From Figure 6-1, a step change in pH is observed when changing the current density. This change in $\mathrm{pH}$ was found to be due to the effect of the potentlal field in the solution on the $\mathrm{pH}$ probe. True $\mathrm{pH}$ 's were obtained by temporarily turning off the galvanostat after which the pH was observed to return to Its previous value in a few seconds.

Figure 6-2 presents the potential of the working electrode relative to a saturated calomel reference electrode located in the chamber adjacent to the artificlal pit. Prior to application of current, the open circuit potential was measured to be in the range -660 to $-600 \mathrm{mV}$. After application of current, the potential rose to a new steady state value indicative of the potential drop through the solution. Since the Initial current density applied was a lways small $\left(0.5 \mathrm{~mA} / \mathrm{cm}^{2}\right)$, the initial IR drop through the solution was small. However, on successive increases in the current density (to $5 \mathrm{~mA} / \mathrm{cm}^{2}$ and $10 \mathrm{~mA} / \mathrm{cm}^{2}$ ), the potential was observed to assume a new ralue rapidly and "quasi" steady state was usually achieved in less than one hour. Unfortunately, the open circult potential was not recorded at each current change and therefore the IR drop alone was not measured.

To determine the error involved In a measurement of $\mathrm{pH}$, a duplicate run for IN NaCl was done under similar conditions to the original experimental run. The same current densities of $0.5,5$, and $10 \mathrm{~mA} / \mathrm{cm}^{2}$ were used for approximately the same length of time. Good agreement was observed at 0.5 $\mathrm{mA} / \mathrm{cm}^{2}$ (see Table 6-1) with the reproduciblilty worsening at higher current densities. The average reproducibility was $0.5 \mathrm{pH}$ units. The reason for the poor reproductbility at high current densities may well be the error associated with placing the probe $1 \mathrm{~mm}$ from the surface of the pit surface. Since steeper concentration gradients are assumed to exist at higher current 
TRANSIENT pH BEHAVIOR FOR 1 N NaC1

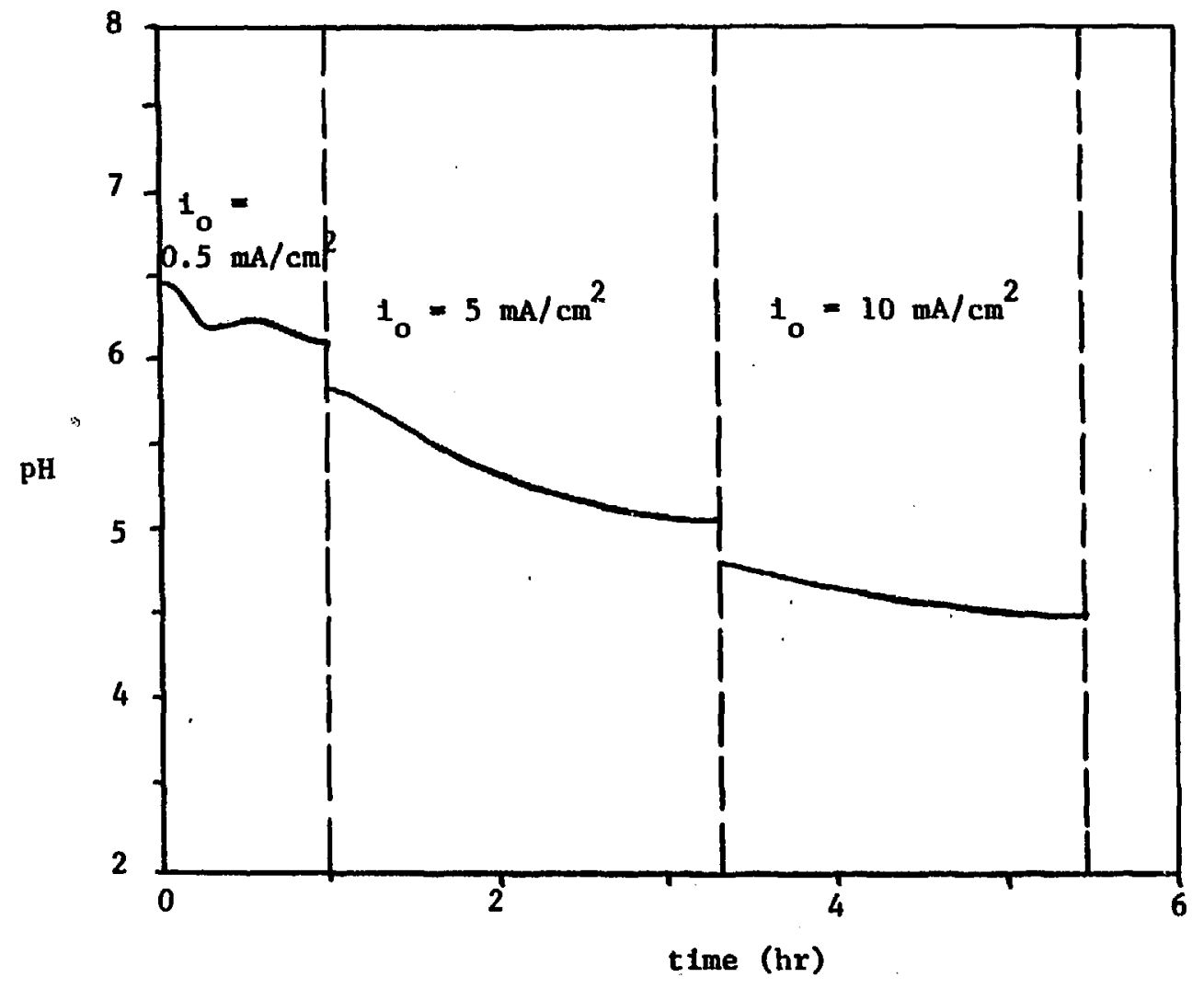


TRANSIENT POTENTIAL BEHAVIOR FOR 1 N NaC1

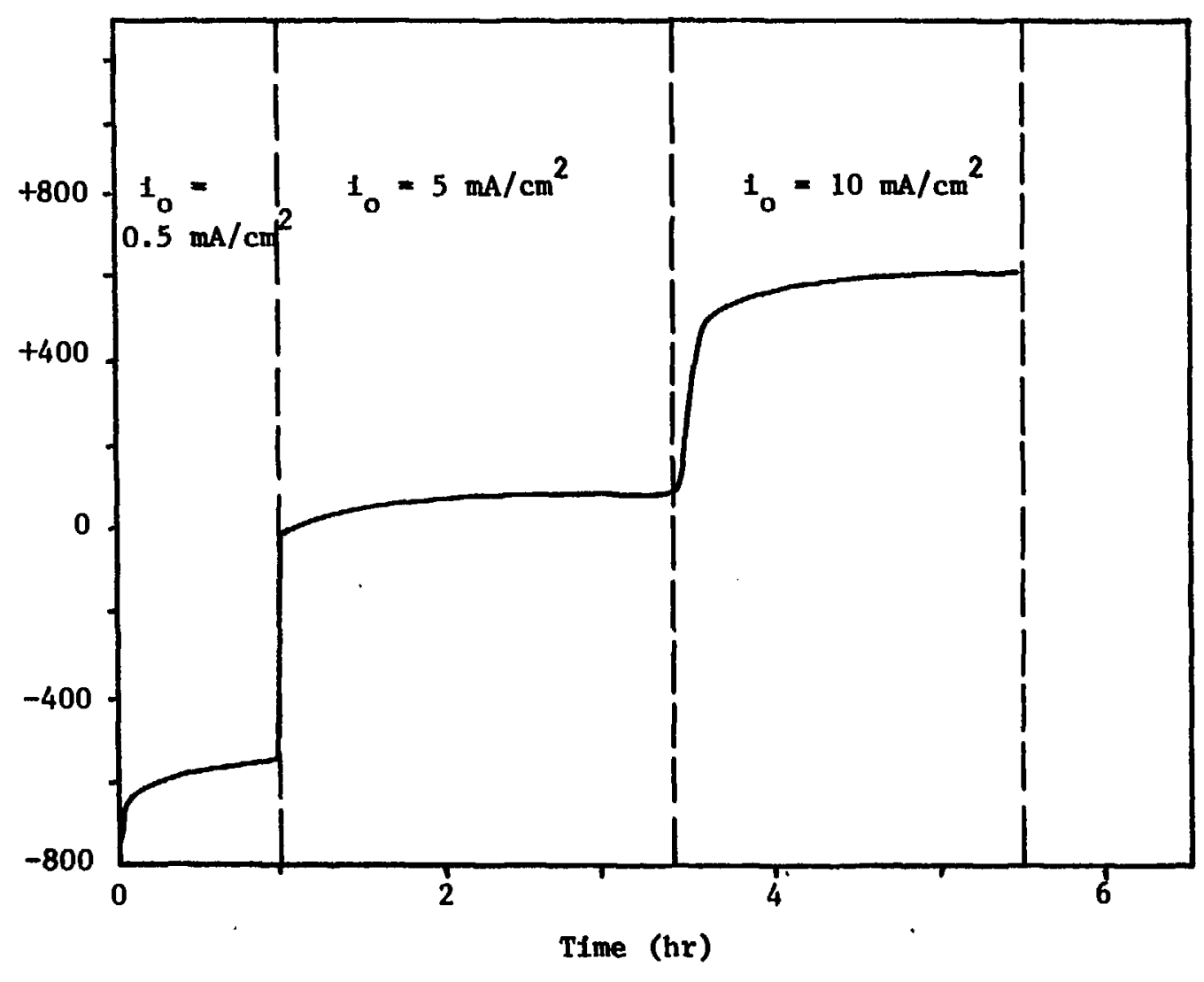


Table 6-1. Reproducibility of the Flat-Bottomed Probe Apparatus - $1 \mathrm{~N}$ NaCl

\begin{tabular}{cccc}
\hline $\begin{array}{c}\text { Current } \\
\text { Density } \\
\left(\mathrm{mA} / \mathrm{cm}^{2}\right)\end{array}$ & $\begin{array}{c}\mathrm{pH} \\
(\text { Run I) }\end{array}$ & $\begin{array}{c}\mathrm{pH} \\
\text { (Run II) }\end{array}$ & $\mathrm{pH}_{\mathrm{I}}-\mathrm{pH}_{\mathrm{II}}$ \\
\hline 0.5 & 6.17 & 6.11 & 0.06 \\
5.0 & 5.10 & 4.60 & 0.50 \\
10.0 & 4.84 & 3.70 & 1.14 \\
\hline
\end{tabular}

densities, the placing of the $\mathrm{pH}$ probe becomes crucial to obtain reproducible results. It is estimated that the error in placing the probe $1 \mathrm{~mm}$ from the pit surface is probably $0.5 \mathrm{~mm}$, sufficient to result in a $\mathrm{pH} \in \mathrm{tror}$ of $0.5 \mathrm{pH}$ units.

\subsection{2 pH Estimation}

Since the $\mathrm{pH}$ probe used in the flat-bottomed probe apparatus was large enough to alter the pH profiles in the pit significantly, it was necessary to account for its presence in the estimation of $\mathrm{pH}$. Through the hydrolysis reactions, ferrous ion profiles are directly related to pH profiles and their shape is assumed similar. The expected ferrous ion concentration profiles in the bottom of the pit as shown in Figure 6-3. The profiles are twodimensional and a rigorous solution was not attempted. Instead, two simplifications were made, each leading to an estimation of the pH as measured by the pH probe.

In the first simplification, Figure 6-4, the layer of fluid between the pit surface and $\mathrm{pH}$ probe was assumed stagnant with the Fet+ dissolving into this layer and a subsequent $\mathrm{pH}$ being established via the hydrolysis reactions (cf. Section 3.1). No transport of ferrous lons up through the annulus was assumed. The composition of the solution under the probe was assumed uniform throughout the layer at any time. Since ferrous lons are continuously being added to the solution, this calculation predicts that the pH will continuously drop and is therefore incapable of predicting "quasi-steady state" pH values. Nevertheless, this method of calculation is expected to provide a lower limit of the pH as measured by the pH probe because the method gives the maximum possible concentration of $\mathrm{Fe}^{++}$. The concentration of $\mathrm{Fe}^{+}$in this layer was calculated at any time, $t$, and any current, $I$, by Faraday's Law:

$$
\left[\mathrm{Fe}^{++}\right]=\frac{\mathrm{It}}{2 \mathrm{FV}}
$$

The volume, $V$, used in this calculation was $0.2011 \mathrm{~cm}^{3}$.

In the second simplification, Figure 6-5, a more complex profile was assumed in which the diffusion of $\mathrm{Fe}^{+t}$ was accounted for. Figure 6-5 depicts the assumed profiles. Two linear profiles were assumed to exist; one in the layer between the probe and $p i t$ surface and another in the annular space 


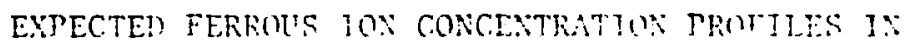

THE AFTTIICIAT, PIT ATTARATIS

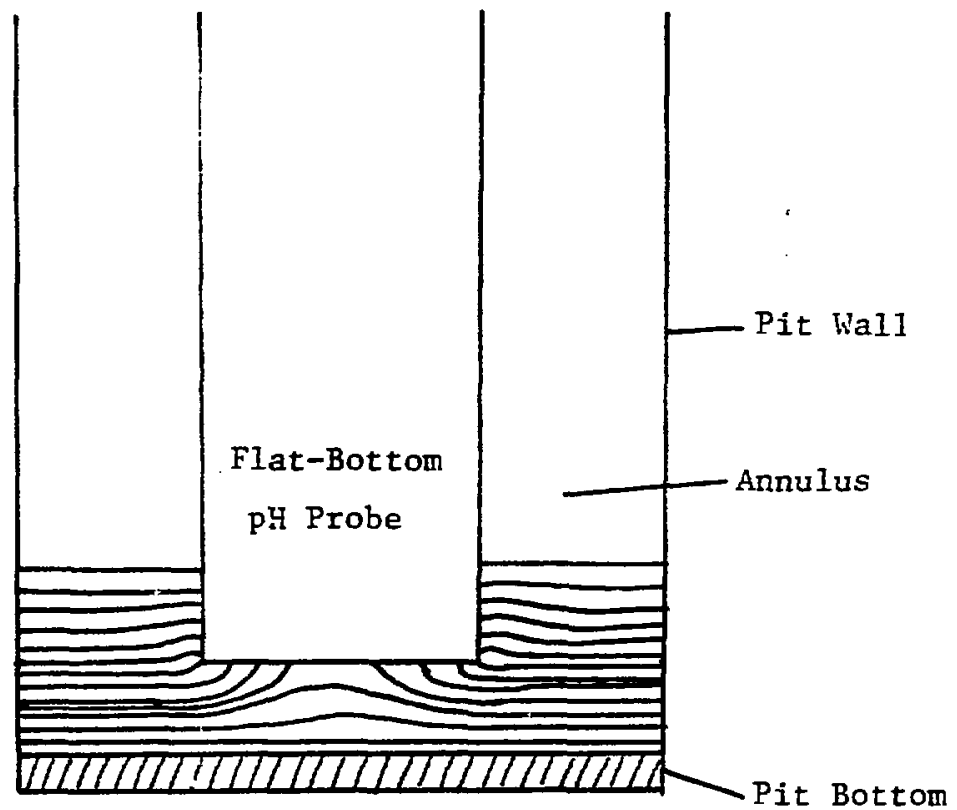

SCHOOL OF CHEMICAL ENGINEERING PAACTICE 


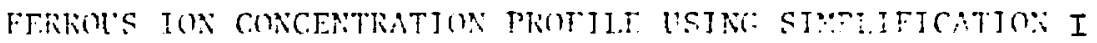

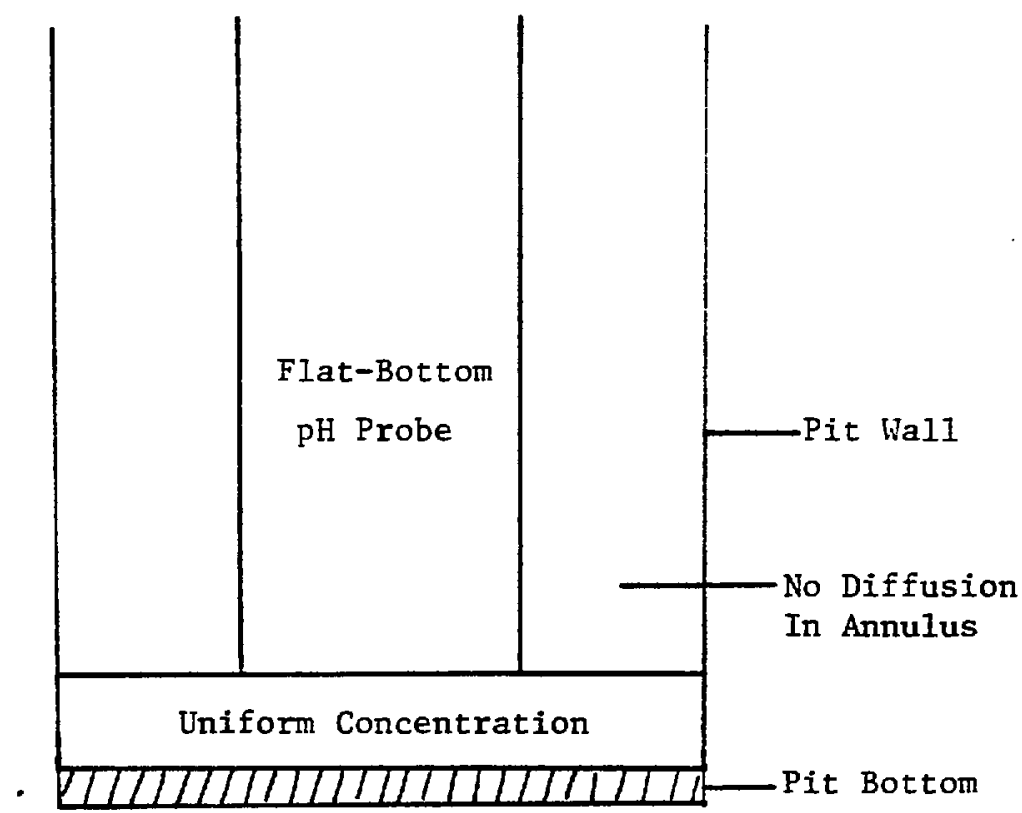

MASSACHUSETTS INSTITUTE OF TECHNOLOGY

SCHOOL OF CHEMICAL ENGINEERING PRACTICE

DATE DRAWN BY

FILE NO. MIT/BNL-86-6

FIG $-40=$ 
FERRULS IOR CONCTXTRGTUN PROFILTS ISING STITLIJJCATION II

Distance from

Pit Bottom

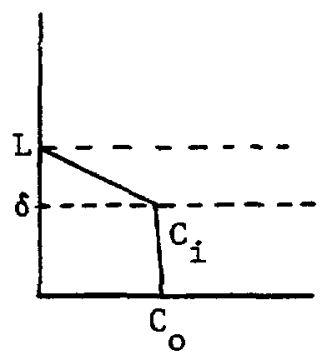

Ferrous Ion Concentration

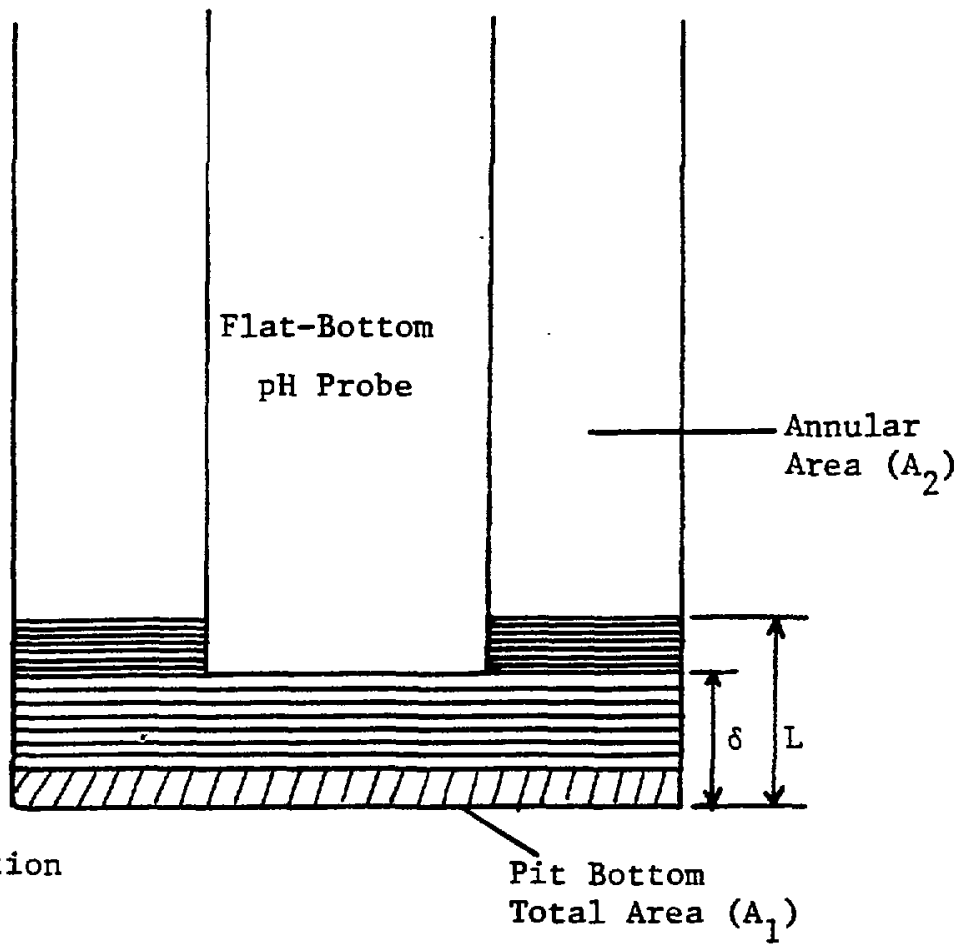

MASSACHUSETTS INSTITUTE OF TECHNOLOGY

SCHOOL OF CHEMICAL ENGINEERING PAACTICE

DATE

$5 / 4 / 86$
ORAWN BY

PW
FIG $\mathrm{MIT} / \mathrm{BNL}-86-6$ 
between the probe and the walls of the artificial pit. The ratio of annular area the total area will be inversely proportional to the concentration gradients in these regions since the total flux must remain constant. We also assume that the concentrationof $\mathrm{Fe}^{++}$will be much greater than the concentration of the hydrolysis products $\mathrm{FeOH}^{+}$and $\mathrm{Fe}(\mathrm{OH})_{2} \cdot$ The concentration profiles for $\mathrm{Fe}^{++}$will therefore be linear:

$$
\frac{\left(\left[\mathrm{Fe}^{++}\right]_{0}-\left[\mathrm{Fe}^{++}\right]_{1}\right)(L-\delta)}{\left(\left[\mathrm{Fe}^{++}\right]_{1}-\left[\mathrm{Fe}^{+t}\right]_{L}\right) \delta}=\frac{A_{2}}{A_{1}}
$$

The total diffusion length was calculated from the time via the expression:

$$
\mathrm{L}^{2}=\mathrm{kDt}
$$

The value of $k$ was chosen so as to yleld $99 \%$ of the bulk conditions at that point. Therefore:

$$
\left[\mathrm{Fe}^{++}\right]_{\mathrm{L}}=0
$$

The "quasi-steady-state" profiles were calculated on the assumption that the rate of ferrous iron diffusion away from the pit surface was equal to the rate of ferrous iron generation, 1.e.,

$$
\frac{\mathrm{D} \mathrm{d}\left[\mathrm{Fe}^{++}\right]}{\mathrm{dX}}=\frac{\mathrm{I}}{2 \mathrm{~F}}
$$

Integrating the above expression from the pit surface to the pH probe bottom, yields

$$
\left[\mathrm{Fe}^{++}\right]_{0}=\left[\mathrm{Fe}^{t+}\right]_{1}+\frac{I}{2 \mathrm{DF}}
$$

Combining Equations $(6-2)$ and $(6-6)$ allows calculations of $\left[\mathrm{Fe}^{++}\right]_{1}$ to be made via

$$
\left[\mathrm{Fe}^{++}\right]_{1}=\frac{\mathrm{IA}_{1}(\mathrm{~L}-\delta)}{2 \mathrm{DFA}_{2}}
$$

It is expected that the second simplification will yield higher values of the $\mathrm{pH}$ than those measured since, in practice, a stagnant region will exist at the surface of the $\mathrm{pH}$ probe resulting in a local increase in Fett concentration and a subsequent decrease in $\mathrm{pH}$.

From the experimental data at "quasi" steady state, ferrous ion concentrations were calculated for the two simplifications and are presented in Figure 6-6 at the corresponding experimental pH values. Also included in the figure is the equilibrium line for the hydrolysis reactions at given values of ferrous ion concentration. The method of calculation of this line is 
presented in Appendix 10.3. The solid points in Figure 6-6 are those calculated from the first simplification and are seen to be above the equilibrium line in almost all cases. This indicates that the first (I) simplification yields ferrous ion concentrations in excess of the amount present, alternatively, the $\mathrm{pH}$ 's calculated from the predicted ferrous ion concentrations are lower than those measured except for large values of the current density. This is as expected since no allowance for fett diffusion beyond the probe was made.

At high current densities, a precipitate was observed to form in the sodium sulfate solutions. According to Sathler, et al (1981), the formation of $\mathrm{FeOOH}$ and $\mathrm{Fe}_{3} \mathrm{O}_{4}$ is thermodynamically possible at the system conditions with a consequent increase in the acidity of the solution due to the reactions

$$
4 \mathrm{Fe}^{++}+6 \mathrm{H}_{2} \mathrm{O}+\mathrm{O}_{2}=4 \mathrm{FeOOH}+8 \mathrm{H}^{+}
$$

or

$$
3 \mathrm{Fe}^{2+}+3 \mathrm{HI}_{2} \mathrm{O}+1 / 2 \mathrm{O}_{2}=\mathrm{Fe}_{3} \mathrm{O}_{4}+6 \mathrm{H}^{+}
$$

It is therefore possible that both of the above precipitations took place at these high current densities producing the low observed pH's. Since the method of calculation of the equilibrium line does not liacorporate the above equilibrium reactions, it cannot account for these low $\mathrm{pH}^{\prime} \mathrm{s}$. We observed that the measured $\mathrm{pH}$ in this region was extremely erratic and sensitive to slight movements in the position of the pH probe. A reliable estimate of the $\mathrm{pH}$ in this region could therefore not be obtained. The recorded potential was also erratic and indicated the possibility of an unstable salt layer forming and breaking down continually. It has also been suggested (Isaacs, 1986) that the reaction:

$$
\mathrm{Fe}+2 \mathrm{H}^{+}=\mathrm{Hm}_{2}+\mathrm{Fe}^{++}
$$

may be possible, and hydrogen bubbles could have produced instabilities.

The open points in Figure 6-6 correspond to ferrous ion concentrations as calculated via the second simplification and are seen to lie below and around the equilibrium curve. The agreement obtained by this simplification is much better than that obtained by the first simplification. This is as expected since the second simplification is a more realistic representation of the true concentration profiles than the first. At low current densities, weasured $\mathrm{pH}^{\prime}$ s were higher than those calculated from simplification 2 for sulfate solutions only. This may well be due to the initial pH of the bulk sulfate solutions. Calculations done on the initial pH of sulfate solutions indicate that a IN $\mathrm{Na}_{2} \mathrm{SO}_{4}$ solution has a $\mathrm{pH}$ of 7.8. Since the experiments were commenced at lower current densities and run for approximately 2 hours before changing current densities, it is expected that the pH attained after 2 hours would be higher than those calculated. The equilibrium line does not account for the slight basicity of sulfate solutions densities. 
CONCENTRATON MF FEREOIS IONS ISINC STMLIFJCATIONS I AND II

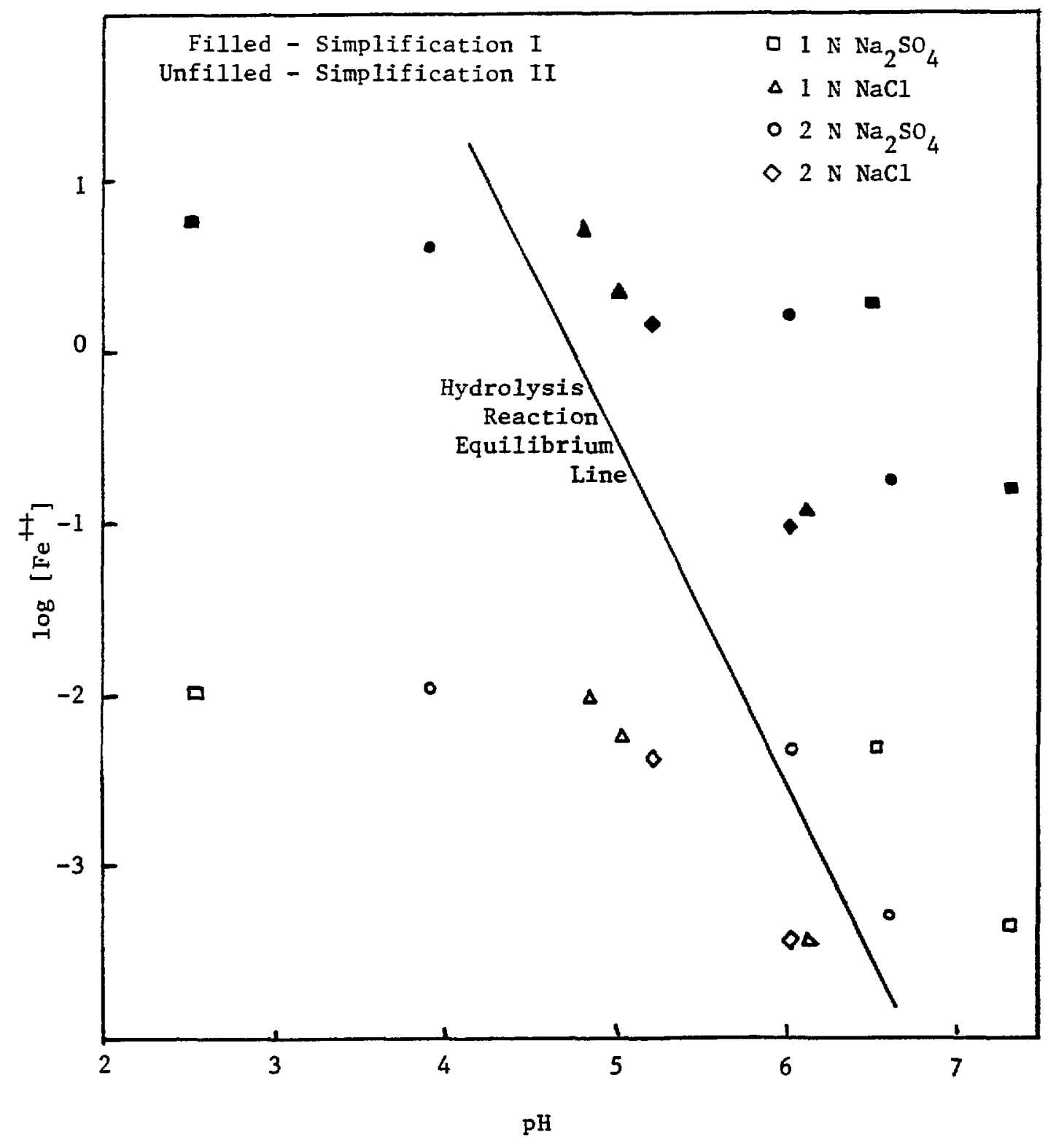

MASSACHUSETTS INSTITUTE OF TECHNOLOGY SCHOOL OF CHEMICAL ENGINEERING PRACTICE 


\subsubsection{Attempted Measurement of the $\mathrm{pH}$ Profile in an Artificial Pit}

To determine the ability of the flat-bottomed probe apparatus to measure the pH profile in a pit, an experimental run was conducted in which the probe was located at the mouth of the pit ( $41 \mathrm{~mm}$ above the iron surface). Once "quasi" steady state had been achieved, the probe was gradually moved into the pit at a rate of $1 \mathrm{~mm}$ every $5 \mathrm{~min}$ until it had reached a position $1 \mathrm{~mm}$ from the pit surface. Since the probe displaces the solution in the pit, it is unlikely that a profile can be measured with any appreciable accuracy. Nevertheless, Figure 6-7 shows an important feature. The bulk pH and pH well into the pit ( $13 \mathrm{~mm}$ from the surface) is very high (10.9) which indicates that $\mathrm{OH}^{-}$ lons are diffusing from the cathode compartment into the anode compartment and into the pit. This is a problen with the flat-bottomed probe apparatus which to some extent was removed in the antimony probe apparatus (as discussed in Section 6.2).

\subsection{Antimony Probe Apparatus}

The antimony probe apparatus was used to obtain pH profiles in an artificial pit. The motivation for building the apparatus was to remove the inadequacies of the flat-bottomed probe apparatus, namely the obtrusive nature of the $\mathrm{pH}$ probe and the diffusion of hydroxide lons into the pit.

\subsection{Behavior of the Antimony pH Probe}

Prior to operation of the antimony probe apparatus, the antimony probe was calibrated with standard buffer solutions. Since it was suspected that the performance of the antimony electrode depended on the presence of oxygen in the system (Wilson, 1970) and oxygen was removed in the solution prior to the operation of the apparatus, it was not known whether these electrodes would operate in the present system. The electrodes were therefore calibrated in ambient dissolved oxygen conditions and de-aerated buffer solutions. The buffer solutions were de-aerated by bubbling $\mathrm{N}_{2}$ gas through the solution for 30 minutes. The probe was also calibrated before each experimental run. The results of these calibrations along with the calibration at ambient dissolved oxygen conditions are presented in Figure 6-8.

Agreement between successive calibration curves is fairly good although at high $\mathrm{pH}$, significant deviation from linearity was observed. There was no apparent effect of de-aeration on the response of the probe. Since the pH measured in the system was always less than 5, the calibration point at pH of 10 was not included. A straight line was regressed excluding these points. The slopes of the individual calibration curves obtained from linear regression to the three $\mathrm{pH}$ data points are included in Figure 6-8 and are seen to agree well (standard deviation $6 \%$ of the mean). Correlation coefficients for the regressions ranged from 0.997 to 0.999 indicating excellent linearity over the pH range of 2 to 7 . Although the calibration curves suggest that the probes are relatively precise, the difference in voltage response of the probe for a given buffer solution may be as large as $1.1 \mathrm{pH}$ units. Since these calibration curves were obtained with the same probe on successive days, the above error seems to suggest "aging" of the probe. According to Wilson (1970), the potential of the antimony electrode varies with the condition of the metal, oxygen content of the solution (although this was not observed), 
PH PROFILF IN THE ARTIFICIAL PIT

AS YLASLRE BY THL FLAT-BOTTOMEI FROBE

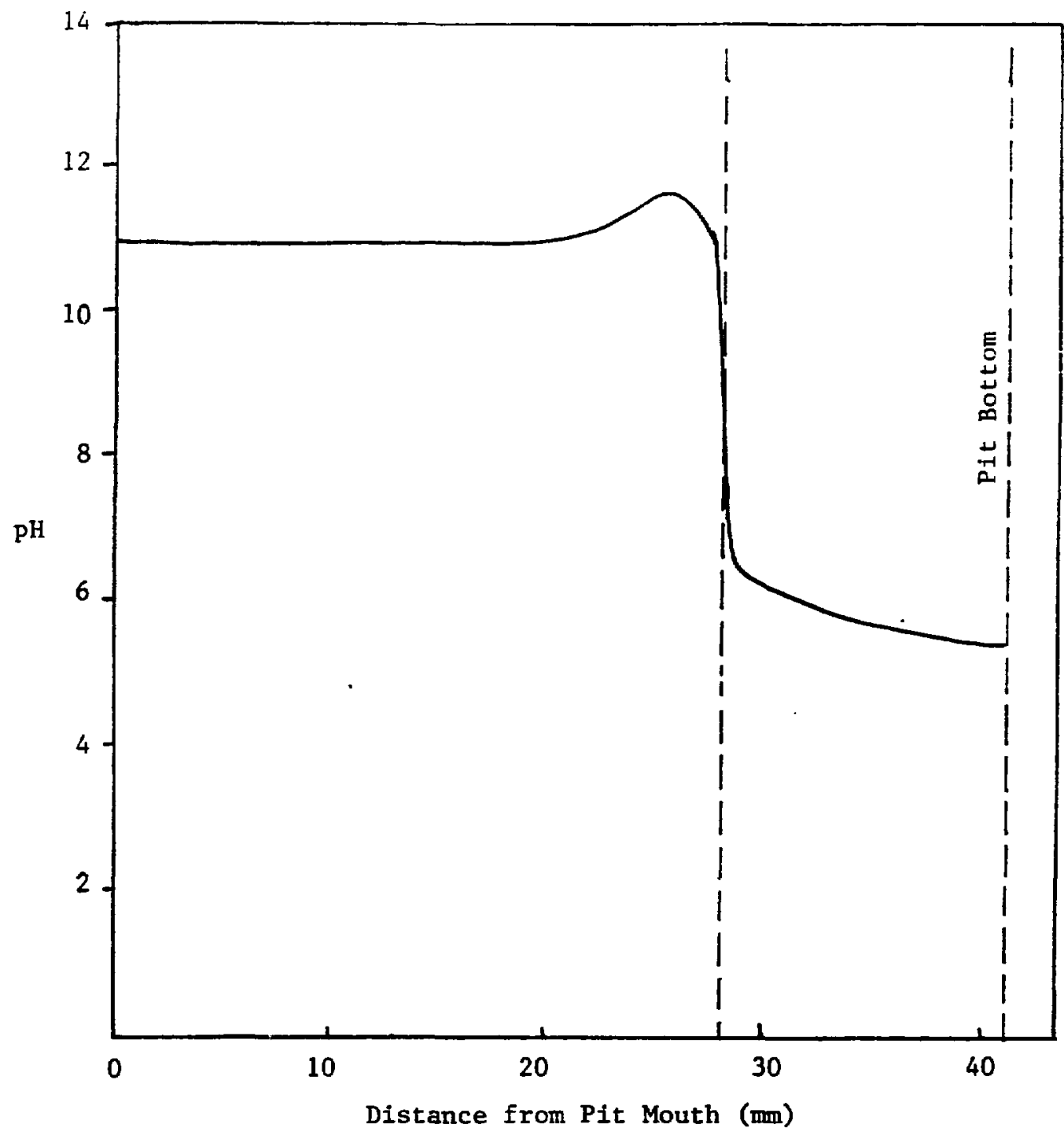


ANTIMONY PROBE CALJBRATIOX

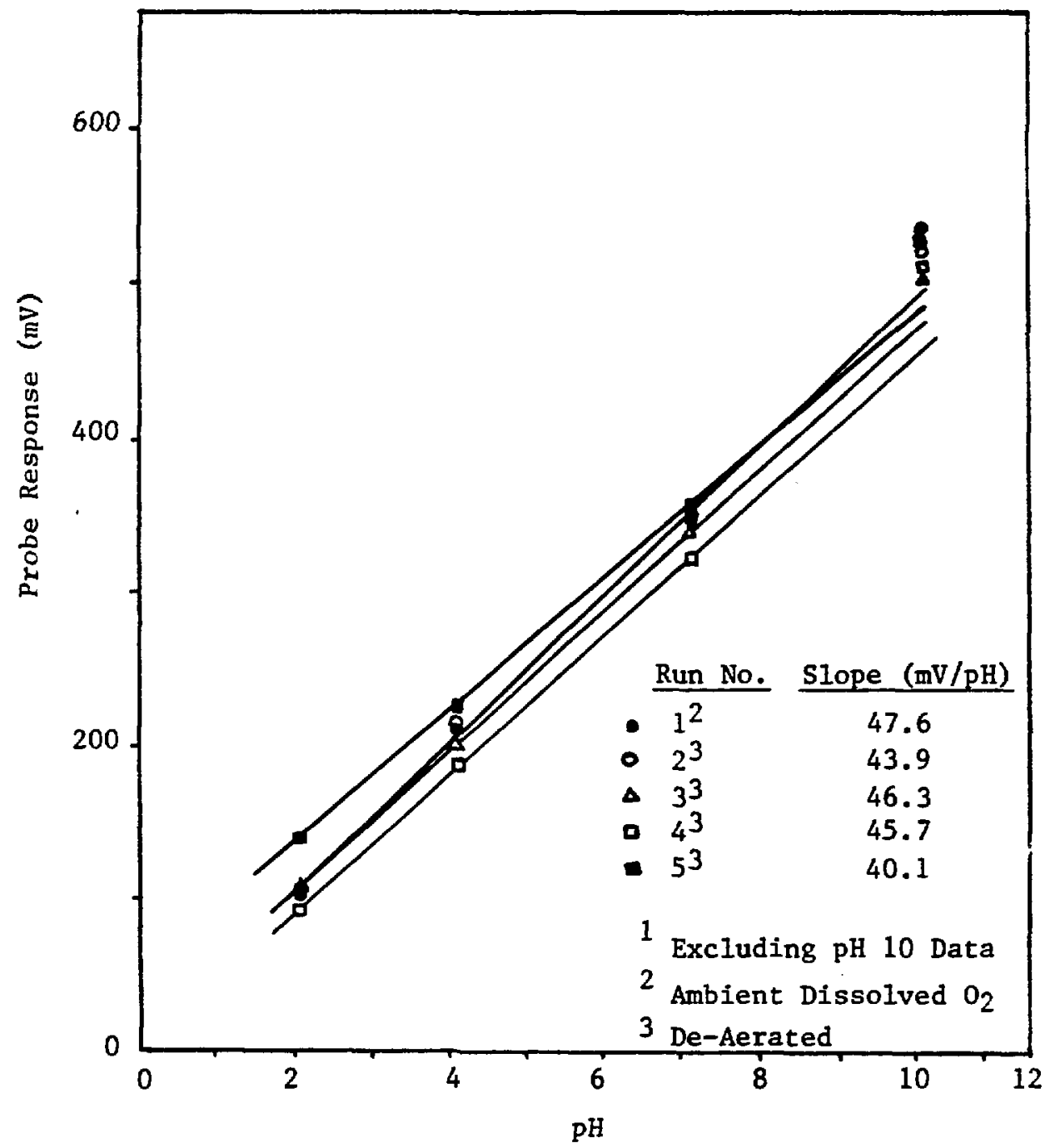

MASSACHUSETTS INSTITUTE OF TECHNOLOGY

SCHOOL OF CHEMICAL ENGINEEAING PAACTICE

DATE

$5 / 4 / 86$
DAAWN EY PW
FIG

MIT/BNL-86-6
6-8 
the rate of stirring of the electrolyte and composition of the buffer solution. The electrode is also senstive to oxidizing and reducing agents in the solution. Wilson suggests a maximum accuracy of $0.1 \mathrm{pH}$ unit.

In addition to calfbration in the buffer solutions, the antimony probes were checked in neutral unbuffered salt solutions. We noticed that while the probes measured $\mathrm{pH}$ reproducibly in the calibration buffer solutions, their performance in strong salt solutions was very different. The pH measurement of the bulk salt solution with an antimony probe and not current applied showed a discrepancy of about $4.2 \mathrm{pH}$ units for $1 \mathrm{M} \mathrm{Na} \mathrm{SO}_{4}$ and $2.6 \mathrm{pH}$ units for $2 \mathrm{~N} \mathrm{Na}_{2} \mathrm{SO}_{4}$ (Table 6-2). Al though the reason for this behavior is not clearly known, it is possible that lonic species affect the formation of the antimony oxide layer on the tip of the probe. The probe depends upon the formation of this oxide layer to respond correctly to changes in pH. Although the probes were shown to be inaccurate, we felt that they could give a qualitative idea of the pH profile in the pit.

Table 6-2. Antimony pH Probe Error

\begin{tabular}{ccc}
$\begin{array}{c}\text { Salt } \\
\text { Solution }\end{array}$ & $\begin{array}{c}\mathrm{pH} \\
\text { Actual }\end{array}$ & $\begin{array}{c}\mathrm{pH} \\
\text { Antimony }\end{array}$ \\
\hline $1 \mathrm{~N} \mathrm{Na}_{2} \mathrm{SO}_{4}$ & 7.8 & 3.6 \\
$2 \mathrm{~N} \mathrm{Na}_{2} \mathrm{SO}_{4}$ & 7.9 & 5.3 \\
\hline
\end{tabular}

\subsubsection{Measurement of $\mathrm{pH}$ Profiles and Comparison with Predicted Profiles}

The $\mathrm{pH}$ profiles in the artificial pit were measured for $1 \mathrm{~N} \mathrm{Na}_{2} \mathrm{SO}_{4}$ at two current densities ( 5 and $7 \mathrm{~mA} / \mathrm{cm}^{2}$ ) and for $2 \mathrm{M} \mathrm{NaCl}$ at one current density ( 5 $\left.\mathrm{mA} / \mathrm{cm}^{2}\right)$. The profiles are presented in Figures $6-9$ and $6-10$. Also shown are the predicted $\mathrm{pH}$ profiles using model I (cf. Section 4.2.1) and the predicted profiles from the model of Galvele (1976). The pH profiles predicted by Model II were substantially lower ( $\mathrm{pH}$ of 0.7 ) than both the experimental and Model I profiles and are not included in Figures $6-9$ and 6-10. This large difference in $\mathrm{pH}^{\prime} \mathrm{s}$ can be attributed to the inapplicability of Model II to large pits. Eor large pits, the large values of current required to maintain constant current density (of $5 \mathrm{~mA} / \mathrm{cm}^{2}$ ) result in large iron dissolution rates and subsequent low $\mathrm{pH}^{\prime} \mathrm{s}$ due to ferrous ion hydrolysis.

The experimentally obtained $\mathrm{pH}$ profiles (Figure 6-9) for equinormal sodium sulfate and sodium chloride solutions at equal current densities are seen to be very similar with the difference easily due to experimental error of the antimony probe. Agreement with predicted profiles from model I is poor with an average $\mathrm{pH}$ difference of 0.8 units. This discrepancy is almost certainly due to the inability of the antimony probe in neasuring the correct $\mathrm{pH}$ of salt solutions. Since it was not known how the accuracy of the antimony probe in salt solutions would vary with $\mathrm{pH}$, no comparison of the model profile slope and experimental profile slope was made. 
COMPARISON OF EXPERIMENTAL DATA (ANTIMONY PROBE) WITH MODEL PREDICTIONS

$\left(i=5 \mathrm{~mA} / \mathrm{cm}^{2}\right)$

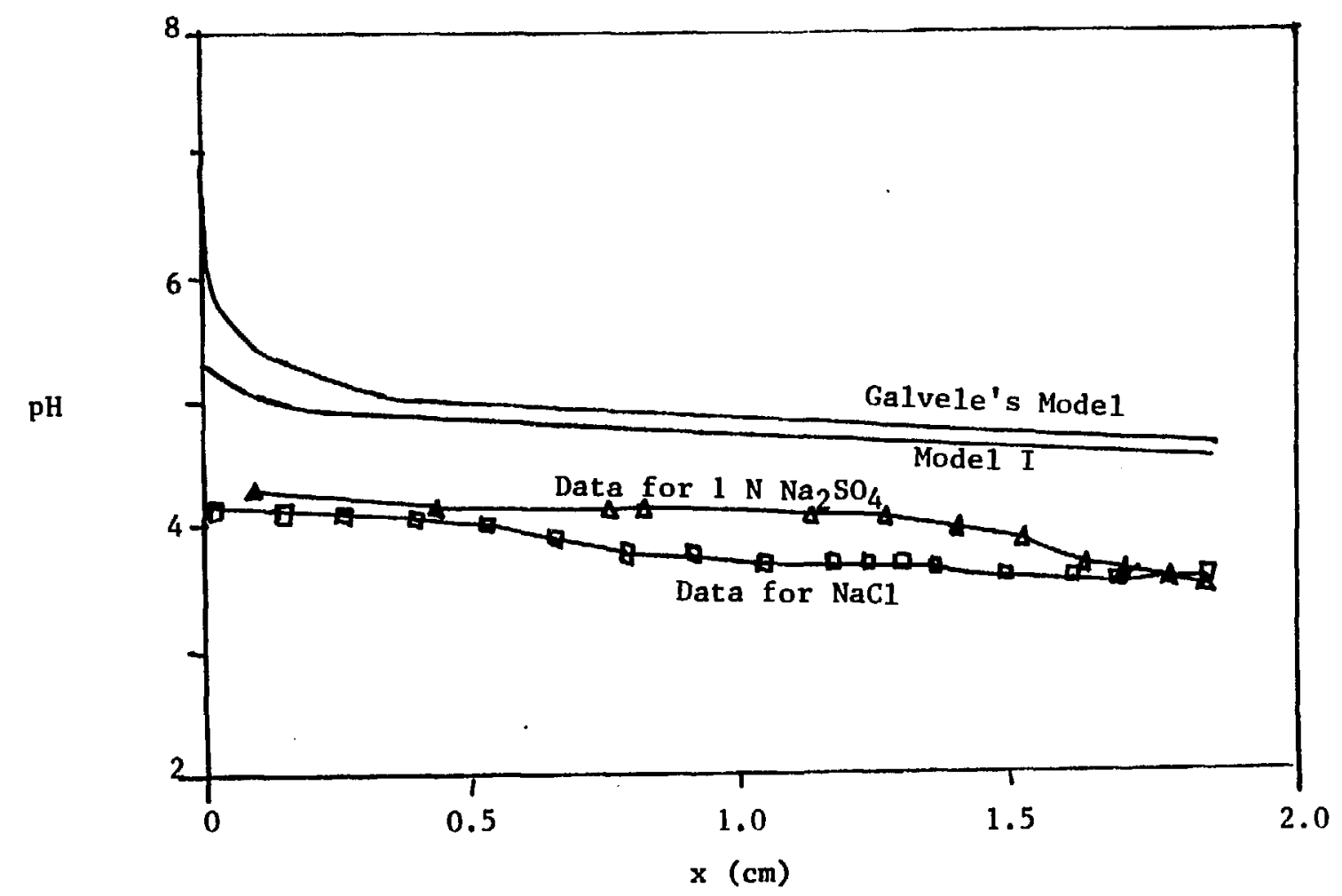


COMPARISON OF EXPERIMENTAL DATA (ANTIMONY PROBE) WITH MODEI. PREDICTIONS $\left(i=7 \mathrm{~mA} / \mathrm{cm}^{2}\right)$




The difference In pH proflles between the model derived and Galvele's model is most pronounced at the pit mouth and decreases as the pit bottom is approached. This is expected since the models differ only in the boundary conditions used at the pit mouth. Galvele uses bulk solution conditions at the pit mouth to solve the profiles in the pit. In the model we derived, the boundary conditions were calculated from considering the pH variation outside the pit.

For the sulfate solution at a higher current density, the overall profile is seen to be much lower than the other salt solutions and the model predictions (a difference of $2 \mathrm{pH}$ units). Again, this difference must be attributed to the poor accuracy obtained in salt solutions.

To test for aging of the probe during a run and to verify the unobtrusive nature of the probe, the profile for sodium sulfate at the higher current density was first obtained by gradually moving the probe out of the pit and then moving the probe back into the pit, taking data points at the same locations. Excellent reproducibility was obtained with a maximum pH change of 0.1 units. Therefore, we concluded that there was no great change in the probe response over the duration of the experiment.

\subsection{Utility of Experimental Apparatuses}

\subsubsection{Flat-Bottomed Probe Apparatus}

The flat-bottomed probe apparatus suffered from two major disadvantages. These were the obtrusive nature of the $\mathrm{pH}$ probe and the diffusion of $\mathrm{OH}^{-}$ions into the pit. The former led to distortion of the pH profiles in the pit and correction for this distortion had to be made in the calculation of pH. It is unlikely that the $\mathrm{pH}$ measured $1 \mathrm{~mm}$ from the pit bottom in this apparatus will be equal to the $\mathrm{pH}$ at this level in the absence of the probe. It is expected that the pH which would have existed in the absence of the probe since the reduction in area leads to a local accumulation of $\mathrm{H}^{+}$ions in the layer beneath the pH probe. The flat-bottomed probe apparatus therefore provides a lower limit of the pH to be expected in the pit.

The diffusion of $\mathrm{OH}^{-}$lons into the pit did not seem to be a problem for experiments in which the probe was located $1 \mathrm{~mm}$ from the pit bottom. The diffusion area was sufficiently reduced to prevent diffusion of $\mathrm{OH}^{-}$to the pit surface through the duration of the experiment. For experiments in which the probe was located at the pit mouth however, a high basicity was recorded and therefore the use of the instrument was restricted to measurements of pH near the surface of the pit.

\subsubsection{Antimony Probe Apparatus}

The antimony probe apparatus suffered from the disadvantage of inaccurate measurement of $\mathrm{pH}$. The utility of the apparatus was in the ability to measure a pH profile reproducibly without disturbing the profile. It is therefore highly likely that the pH profile in the absence of the probe would be very similar to that in the presence of the probe. 


\subsubsection{Comparison of Apparatuses}

Since the flat bottomed probe apparatus will yleld low values of the pH in the artificial pit (and it is not known how low in relation to the true value), comparison to the antimony probe apparatus is not meaningful especially since the accuracy of the antimony probes was very poor.

\subsection{Results from Other Apparatuses}

Prior to operation of the flat bottomed probe and antimony probe apparatuses, several other apparatuses and methods of measuring pH were used. An apparatus similar to the flat bottomed probe apparatus was used except that a fourth compartment was attached to the system ria a salt bridge and the cathode located in this compartment. This was done in an effort to reduce diffusion of $\mathrm{OH}^{-}$ions from the cathode into the pit. However, the subsequent increase in potential drop through the salt bridge limited the maximum current density obtainable to $0.5 \mathrm{~mA} / \mathrm{cm}^{2}$ since at this current, the galvanostat was unable to provide sufficient voltage to overcome the resistance of the electrolyte. At this low current density, the corrosion rate is too low to obtain "quasi" steady $s$ tate in a practical amount of time.

Due to the difficulty in measuring a point $\mathrm{pH}$ in the pit, several methods of $\mathrm{pH}$ measurement were tried. In one experiment, the pH probe was replaced with $\mathrm{pH}$ indicator paper which lay on its side on the surface of the pit. However, the $\mathrm{pH}$ paper did not respond to changes in $\mathrm{pH}$ in the pit. It was observed that the color did not change when exposed to a new pH unless the electrolyte is vigorously stirred. This is undesirable since the pH profiles would be destroyed.

pH indicator solution (Bromocresol green) which changed color from yellow to blue in the pH range 4.2 to 5.4 was added to the electrolyte and the $\mathrm{pH}$ probe removed. No color change was observed in the solution and any change which might have occurred near to the metal surface was obscured by formation of a salt layer. 


\section{CONCLUSIONS}

Two artificial pit apparatuses were constructed in an attempt to determine the $\mathrm{pH}$ at the surface of a one-dimensional pit and in the solution above the pit surface.

\subsection{Flat-Bottomed Probe Apparatus}

The pH values obtained with the flat-bottomed probe apparatus were in the range 4.8 to 7.3 for a range of salt solutions ( $\mathrm{NaCl}$ and $\mathrm{Na}_{2} \mathrm{SO}_{4}$ were used) and current densities $\left(0.5,5\right.$ and $\left.10 \mathrm{~mA} / \mathrm{cm}^{2}\right)$. Two simplifications were made to account for the effect of the probe on the pH profiles. The first was found to predict lower $\mathrm{pH}^{\prime} \mathrm{s}$ than observed. This was expected due to the inherent nature of the simplification. At high current densities, for the sulfate solutions only, a lower pH was observed than calculated by either simplification possibly due to the formation of a precipitate. The results for chloride solutions using the second simplification were very close to those expected from equilibrium considerations.

\subsection{Antimony Probe Apparatus}

The results obtained from the antimony probe apparatus were much lower than those obtained with the flat bottomed probe apparatus (approximately $2 \mathrm{pH}$ units). Calibration of the antimony probes indicated that al though good reproducibility was obtained in buffer solutions, the pH measurement of salt solutions gave values approximately $2 \mathrm{pH}$ units too low. We did not observe a difference in pH profiles between chloride and sulfate solutions. The antimony probes are therefore not suitable for accurate measurement of $\mathrm{pH}$.

\subsection{Modeling pH Varlations}

The antimony probe apparatus gave $\mathrm{pH}^{\prime} \mathrm{s}$ of approximately 2 units lower than the model prediction, although the shape of the pH profile was in good agreement with that predicted. The discrepancy was again due to the inability of the antimony $\mathrm{pH}$ probes to measure the $\mathrm{pH}$ accurately. Because of the accuracy of the probes, the model could not be verified.

The model predicts that at pit initiation conditions $\left(i=1 \mathrm{~A} / \mathrm{cm}^{2}, r=10^{-6}\right.$ $\mathrm{cm}$ ), the $\mathrm{pH}$ at the mouth of the pit is lower than that of the bulk solution. The acidification is great enough that it should be detectable (at least 0.25 pH unit).

The two models derived predict that at pit initiation conditions $(i=1$ $\left.A / \mathrm{cm}^{2}, r=10^{-6} \mathrm{~cm}\right)$, the concentration of iron at the mouth of the $\mathrm{pit}$ is on the order of $10^{-3} \mathrm{M}$. Both models predict $\mathrm{Fe}(\mathrm{OH})_{2}$ concentrations outside the pit that are well below the solubility limits of $\mathrm{Fe}(\mathrm{OH})_{2}$.

For a bulk solution of $\mathrm{pH} 10$, there is a critical value of $i_{0} r_{0}\left(10^{-6}\right.$ $A / \mathrm{cm})$ above which there is a sharp $\mathrm{pH}$ decrease. The model predicted pH profiles around the $\mathrm{p}$ it and indicated that the $\mathrm{pH}$ at the mouth of the pit may be as low as 5 for a pit of radius $10^{-6} \mathrm{~cm}$. This would lead to depassivation of the surrounding area and subsequent growth of the plt. However, since the 
criteria for depassivation is not well understood, prediction of pit growth is not possible. 


\section{RECOMMENDATIONS}

1. An apparatus similar to the antimony probe apparatus should be used to obtain $\mathrm{pH}$ profiles in and above the one-dimensional pit. The antimony probe should be replaced with glass membrane micro-probes to obtain accurate $\mathrm{pH}^{\prime} \mathrm{s}$.

2. To obtain realistic values of $\mathrm{pH}^{\prime} \mathrm{s}$ to be expected in pitting, micro probes should be used to scan the surface of a metal. In this way, areas of local acidification can be located and pH profiles around pits measured.

3. A refined model should be developed to account for precipitation of salt species in the $p$ it and two dimensional flux of lonic species out of the pit. A cathodic reaction taking place Immediately adjacent to the pit should be incorporated into the model.

4. Measurement of open-clrcuit potential and $\mathrm{pH}$ in a pit apparatus will allow determination of the true solution IR drop to be made and permit determination of the cathodic and anodic reactions occurring in the system. This will allow a more comprehensive model to be derived for pitting. 


\section{ACKNOWLEDGMENTS}

We would like to acknowledge the assistance we received from our consultants, Gustavo Cragnolino and Hugh Isaacs, and thank them for taking the time to answer our questions. We also are grateful to Don Becker for helping us construct our experimental apparatuses, especlally the fabrication of the antimony probes. Without Don, we could not have performed the experimental work. 


\section{AP PENDIX}

\subsection{Nomenclature}




Mode1 I

Equation 4-54 is an approximation of the rigorous expression relating $r$ and $\mathrm{pH}$, valid at low $\mathrm{pH} ' \mathrm{~s}$ :

$$
\log \left(r / r_{0}\right)-\log \left(i_{0} r_{0}\right)=\log \left(\frac{D_{4} K_{1} K_{w}}{2 F D_{1} D_{5}}\right)+2(p H+3)
$$

At the mouth of the pit, $r=r_{0}$ :

$$
2 \mathrm{pH}_{0}+6=-\log \left(1_{0} \mathrm{r}_{0}\right)-\log \left(\frac{\mathrm{D}_{4} \mathrm{~K}_{1} \mathrm{~K}_{\mathrm{w}}}{2 \mathrm{FD}_{1} \mathrm{D}_{5}}\right)
$$

Given the values in Table 4-1:

$$
\begin{aligned}
& D_{1}=D_{4}=1 \times 10^{-5} \mathrm{~cm}^{2} / \mathrm{s} \\
& D_{5}=5.3 \times 10^{-5} \mathrm{~cm}^{2} / \mathrm{s} \\
& k_{1}=10^{7.5}\left(\mathrm{~cm}^{3} / \mathrm{mol}\right) \\
& K_{w}=10^{-20}\left(\operatorname{mol} / \mathrm{cm}^{3}\right)^{2} \\
& F=96500 \mathrm{C} / \mathrm{eq} \\
& 2 \mathrm{pH}_{0}=\log \left(i_{0} \mathrm{r}_{0}\right)-\log \left(3.1 \times 10^{-14}\right)-6 \\
& 2 \mathrm{pH}_{0}=7.5-\log \left(i_{0} r_{0}\right) \\
& \mathrm{pH}_{0}=3.75-(1 / 2) \log \left(1_{0} r_{0}\right)
\end{aligned}
$$

Mode1 II

Equation (4-56) is an approximation of the rigorous expression relating $r$ and $\mathrm{pH}$, valid at low $\mathrm{pH}^{\prime} \mathrm{s}$ :

$$
\log \left(r / r_{0}\right)-\log \left(I_{0} r_{0}\right)=\log \left(1 / F D_{5}\right)+p H+3
$$

At the pit mouth, $r=r_{0}$ :

$$
\begin{aligned}
& -\log \left(I_{0} \Gamma_{0}\right)=\log \left(1 / F D_{5}\right)+\mathrm{pH}_{0}+3 \\
& \mathrm{pH}_{0}=0.71-3-\log \left(i_{0} \Gamma_{0}\right) \\
& \mathrm{pH}_{0}=-2.29-\log \left(i_{0} \Gamma_{0}\right)
\end{aligned}
$$




\subsection{Calculation of the $\mathrm{pH}$ of a Ferrous Ion Solution}

Given that an initial amount of ferrous ions are added to a known volume of water, we need to calculate the resultant of the solution. The hydrolysis reactions considered are:

$$
\begin{gathered}
\mathrm{Fe}^{++}+\mathrm{H}_{2} \mathrm{O} \rightleftharpoons \mathrm{Fe}(\mathrm{OH})^{+}+\mathrm{H}^{+} \\
\mathrm{Fe}(\mathrm{OH})^{+}+\mathrm{H}_{2} \mathrm{O} \rightleftharpoons \mathrm{Fe}(\mathrm{OH})_{2}+\mathrm{H}^{+}
\end{gathered}
$$

and the self-dissociation of water is

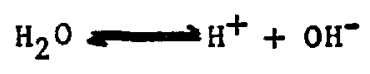

We assume that:

a) $\mathrm{Fe}(\mathrm{OH})_{2}$ is in the aqueous forn and does not precipitate

b) The presence of a salt does not affect the equations since the anions and cations are contributed in equal amounts.

c) No ferrous salts precipitate

For Reactions $(10-4)$ to $(10-6)$, the equilibrium constants are:

$$
\begin{aligned}
& K_{1}=10^{-9.5} \mathrm{~mol} / 1=\frac{\left[\mathrm{Fe}(\mathrm{OH})^{+}\right]\left[\mathrm{H}^{+}\right]}{\left[\mathrm{Fe}^{+}\right]}
\end{aligned}
$$

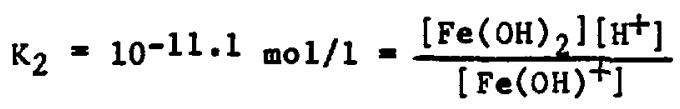

$$
\begin{aligned}
& K_{w}=10^{-14} \mathrm{~mol}^{2} / 1^{2}=\left[\mathrm{H}^{+}\right]\left[\mathrm{OH}^{-}\right]
\end{aligned}
$$

If $\left[\mathrm{Fe}^{++}\right]_{0}$ is the initial concentration of ferrous ions in the solution, then a ferrous ion balance gives;

$$
\left[\mathrm{Fe}^{++}\right]=\left[\mathrm{Fe}^{++}\right]_{0}-\left[\mathrm{Fe}(\mathrm{OH})^{+}\right]-\left[\mathrm{Fe}(\mathrm{OH})_{2}\right]
$$

Since ferrous ions are being added to a neutral solution, a net positive charge is built up (which in a real pit is balanced by diffusion of the anion in solution to the metal surface). The charge balance therefore gives;

$$
2\left[\mathrm{Fe}^{++}\right]+\left[\mathrm{H}^{+}\right]+\left[\mathrm{Fe}(\mathrm{OH})^{+}\right]-\left[\mathrm{OH}^{-}\right]=2\left[\mathrm{Fe}^{++}\right]
$$

The unknown concentrations in the solution are $\left[\mathrm{Fe}^{++}\right],\left[\mathrm{H}^{+}\right],\left[\mathrm{OH}^{-}\right],\left[\mathrm{Fe}(\mathrm{OH})^{+}\right]$ and $\left[\mathrm{Fe}(\mathrm{OH})_{2}\right]$. 
Since we have five equations $(10-7)$ to $(10-11)$, a solution for $\left[\mathrm{H}^{+}\right]$is possible.

By successive substitution and elimination of the equations (the details of which are included in calculation file MIT/BNL - 86-6), a quartic equation in $\mathrm{H}^{+}$] is obtained:

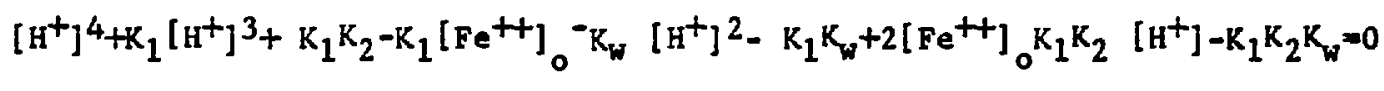

Equation (10-12) allows the $\mathrm{pH}$ of the solution to be calculated given the initial ferrous ion concentration.

\subsection{Location of Original Data}

The original experimental data can be found in Laboratory Databook MIT/BNL-86-6 located at the M.I.T. School of Chemical Engineering Practice, Building 120, Erookhaven National Laboratory, Upton, NY 11973. 


\section{REFERENCES}

Alvarez, M.G. and J.R. Galvele, J.Electrochem. Soc., 127, 1235 (1980).

Bockris, J. and A.K.N. Reddy, Modern Electrochemistry, Plenum Press, NY, Chapter $11(1970)$.

Galvele, J.R., "Transport Process and the Mechanism of Pitting of Metals," J. Electrochem. Soc., 123, 464 (1976).

Galvele, J.R., "Transport Process in the Passivity Breakdown-II. Full Hydrolysis of the Metal Ions," Corros. Sci, 21, 551 (1981).

Gravano, S.M. and J.R. Galvele, "Transport Processes in Passivity BreakdownIII. Full Hydrolysis plus Ion Migration plus Buffers," Corros. Sc1., $24(6), 517(1984)$.

Isaacs, H.S., "Pitting Corrosion," Brookhaven National Laboratory, Technical Report A-3269 1-85 (January 1985).

Isaacs, H.S., personal communication, Research Scientist, Brookhaven National Laboratory, Upton, NY (1986).

Kuhn A.T., and C.Y. Chan, "pH Changes at Near-Electrode Surfaces," J. Appl. Electrochem., 13, 189 (1983).

Newman, J., Electrochemical Systems, Prentice-Ha 11, Englewood Cliffs, NJ (1973).

Pourbaix, M., Atlas of Electrochemical Equilibria in Aqueous Solutions, National Association of Corrosion Engineers, Houston, TX (1974).

Rosebrugh, T.R. and W. Lash-M11ler, J. Phys. Chen., 14, 816 (1910).

Sathler, I., J. Van Muylder, R. Winand, and M. Pourbalx, "Electrochemical Behaviour of Iron in Localized Corrosion Cells in the Presence of Chloride," CEBELCOR and Free University of Brussels, (1981).

Uhlig, H., Corrosion and Corrosion Control, John Wiley and Sons, Inc., NY (1971).

Wilson, A., pH Meters, Barnes and Noble, NY (1970). 